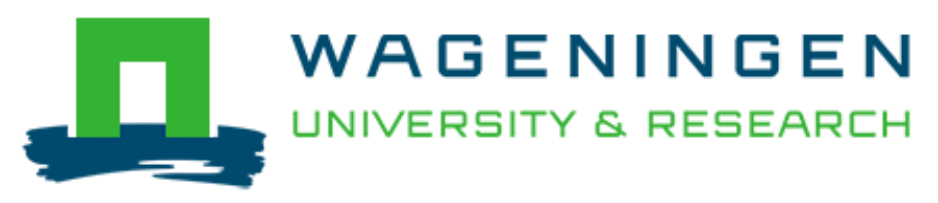

\title{
Non-destructive tree volume estimation through quantitative structure modelling: Comparing UAV laser scanning with terrestrial LIDAR
}

Brede, B., Calders, K., Lau, A., Raumonen, P., Bartholomeus, H. M., Herold, M., \& Kooistra, L.

This is a "Post-Print" accepted manuscript, which has been Published in "Remote Sensing of Environment"

This version is distributed under a non-commercial no derivatives Creative Commons (C) $(1) \Theta$ reproduction in any medium, provided the original work is properly cited and not used for commercial purposes. Further, the restriction applies that if you remix, transform, or build upon the material, you may not distribute the modified material.

Please cite this publication as follows:

Brede, B., Calders, K., Lau, A., Raumonen, P., Bartholomeus, H. M., Herold, M., \& Kooistra, L. (2019). Non-destructive tree volume estimation through quantitative structure modelling: Comparing UAV laser scanning with terrestrial LIDAR. Remote Sensing of Environment, 233, [111355]. https://doi.org/10.1016/j.rse.2019.111355

You can download the published version at:

https://doi.org/10.1016/j.rse.2019.111355 


\title{
Non-destructive Tree Volume Estimation through Quantitative Structure Modelling: Comparing UAV Laser Scanning with Terrestrial Lidar
}

\author{
Benjamin Brede ${ }^{\mathrm{a}}$, Kim Calders ${ }^{\mathrm{b}}$, Alvaro Lau ${ }^{\mathrm{a}}$, Pasi Raumonen ${ }^{\mathrm{c}}$, Harm M. Bartholomeus ${ }^{\mathrm{a}}$, \\ Martin Herold ${ }^{a}$, Lammert Kooistra ${ }^{a}$ \\ ${ }^{a}$ Wageningen University $\&$ Research, Laboratory of Geo-Information Science and Remote Sensing, \\ Droevendaalsesteeg 3, 6708 PB Wageningen, The Netherlands \\ ${ }^{b}$ CAVElab - Computational \&3 Applied Vegetation Ecology, Ghent University, Belgium \\ ${ }^{c}$ Tampere University, Korkeakoulunkatu 7, 33720 Tampere, Finland
}

\section{Abstract}

Above-Ground Biomass (AGB) product calibration and validation requires ground reference plots at hectometric scales to match space-borne missions' resolution. Traditional 3 forest inventory methods that use allometric equations for single tree AGB estimation suffer 4 from biases and low accuracy, especially when dealing with large trees. Terrestrial Laser 5 Scanning (TLS) and explicit tree modelling show high potential for direct estimates of tree 6 volume, but at the cost of time demanding fieldwork. This study aimed to assess if novel 7 Unmanned Aerial Vehicle Laser Scanning (UAV-LS) could overcome this limitation, while 8 delivering comparable results. For this purpose, the performance of UAV-LS in comparison 200 trees with Diameter at Breast Height (DBH) ranging from 6 to $91 \mathrm{~cm}$ from 5 stands, 11 including coniferous and deciduous species, have been scanned, segmented and subsequently

scanner point clouds. Direct comparison with TLS derived models showed that UAV-LS

was reliably modelling volume of trunks and branches with diameter $\geq 30 \mathrm{~cm}$ in the mature beech and oak stand with Concordance Correlation Coefficient (CCC) of 0.85 and RMSE of $1.12 \mathrm{~m}^{3}$. Including smaller branch volume led to a considerable overestimation and decrease in correspondence to CCC of 0.51 and increase in RMSE to $6.59 \mathrm{~m}^{3}$. Denser stands prevented sensing of trunks and further decreased CCC to 0.36 in the Norway spruce stand. Also small, 
young trees posed problems by preventing a proper depiction of the trunk circumference and decreased CCC to 0.01. This dependence on stand indicated a strong impact of canopy structure on the UAV-LS volume modelling capacity. Improved flight paths, repeated acquisition flights or alternative modelling strategies could improve UAV-LS modelling performance under these conditions. This study contributes to the use of UAV-LS for fast tree volume and AGB estimation on scales relevant for satellite AGB product calibration and validation. Keywords:

Laser Scanning, UAV, Forest, Above-Ground Biomass (AGB), Quantitative Structure Model (QSM)

\section{Introduction}

Terrestrial vegetation contains approximately 450 to $650 \mathrm{PgC}$, which is on the same order of magnitude as the atmospheric carbon pool (Ciais et al., 2013) and forests make up a significant contribution to the vegetation carbon pool. However, the forest carbon pool is only weakly constrained due to a low and possibly biased number of sample plots worldwide (Houghton et al., 2009). The future ESA BIOMASS (Le Toan et al., 2011), NASA GEDI (https://science.nasa.gov/missions/gedi) and NISAR (NASA ISRO SAR) missions aim to improve observations of Above-Ground Biomass (AGB) on global scales with a focus on forests. This underpins the space agencies' commitment towards global AGB mapping capabilities.

Even though general relationships between satellite sensor signals and AGB for the intended missions are well established - e.g., exponential relationship for Synthetic Aperture Radar (SAR) backscatter intensity and AGB - specific retrieval models have to be calibrated based on ground reference plots (Saatchi et al., 2011; Baccini et al., 2012; Thiel and Schmullius, 2016). This means calibration at the scale of the satellite's mapping unit are required, which are typically hectometric for AGB. If best practice for validation of geophysical products shall be followed, the observation's geo-location error has to be considered, which usually means to triplicate the calibration unit side length (Fernandes et al., 2014). Additionally, a large number of plots is required to capture the heterogeneity of stand structural characteristics 
across an area of interest. For example, Saatchi et al. (2011), Baccini et al. (2012) and Mitchard et al. (2014) used data from 4079, 283 and 413 inventory plots to build maps for (pan-)tropical forests, respectively. Furthermore, uncertainty in traditional field inventory biomass assessment based on allometric equations is high. Contributing to this is the limited availability of calibration samples for allometric model generation, which need to be destructively harvested, and application of allometric models outside of the area where they have been developed (Yuen et al., 2016).

Given above-mentioned circumstances, calibration of satellite-based AGB products is already challenging. But in the light of systematic global AGB product validation, a significant number of globally and temporally representative in situ sites, and systematic re-validation of the product's time series is required as envisaged by the Committee on Earth Observation Satellites (CEOS) Land Product Validation (LPV) subgroup. This requires accurate and fast techniques that cover the satellite footprint. Forest inventory techniques can achieve the speed and coverage, but lack accuracy in tropical forests (Disney et al., 2018).

Terrestrial Laser Scanning (TLS) has been proposed as an alternative to traditional inventory techniques for AGB assessment (Disney et al., 2018). Compared to the latter it has shown nearly unbiased AGB estimates, which is particularly critical for large trees (Keller et al., 2001; Calders et al., 2015b; Gonzalez de Tanago et al., 2018). Another advantage of TLS is that it does not require destructive sampling. Several studies have demonstrated the effectiveness of TLS for AGB assessment (Calders et al., 2015b; Hackenberg et al., 2015; Rahman et al., 2017; Momo Takoudjou et al., 2018; Gonzalez de Tanago et al., 2018; Stovall et al., 2017; Stoval and Shugart, 2018) and best practices for field set-ups begin to be established (Wilkes et al., 2017). Currently, the LPV guideline for good practices in AGB validation is being compiled, which also includes a section on TLS.

However, a drawback of TLS-based AGB inventories is the time consuming field work. For the acquisition of a dataset that allows reliable geometrical modelling, an experienced team requires 3 to 6 days for a 1 ha plot (Wilkes et al., 2017). Good quality data for geometrical modelling means low occlusion of canopy elements, which makes it necessary to use multiple scan locations in the plot and accurately co-register them. 
Recently, miniaturisation and advancement in several Unmanned Aerial Vehicle (UAV) components has prepared the ground for the construction of Unmanned Aerial Vehicle Laser Scanning (UAV-LS) systems. The critical challenge in this context is the high position and orientation accuracy requirement of the scanner at any time during data acquisition. This determines the geometric accuracy of the produced point cloud. In the contrasting case of TLS, positioning of the scanning positions relative to each other is provided with common targets, most often retro-reflectors, and scan positions are limited to tens to few hundreds per plot (Wilkes et al., 2017). For UAV-LS, the position has to be determined several times per second for flight times of up to 30 min to provide the necessary information for accurate target localisation, which is more comparable to Airborne Laser Scanning (ALS) conditions.

Another difference of UAV-LS to TLS is the perspective above the canopy. From this perspective trunks, which contain the largest part of biomass, are at least partly occluded by upper branches or leaves (Brede et al., 2017). For example, Schneider et al. (2019) found that $71 \%$ of the canopy up to $25 \mathrm{~m}$ above ground are occluded in a temperate forest when observed with UAV-LS. Finally, UAV-LS point cloud densities are limited by scanner speed and flight time. Recent UAV-LS systems have produced point clouds with densities of around 50 (Wallace et al., 2012), 1500 (Jaakkola et al., 2010; Mandlburger et al., 2015) and 4000 points $/ \mathrm{m}^{2}$ (Brede et al., 2017). TLS plot scans have typically point densities of tens of thousands points $/ \mathrm{m}^{2}$ (Brede et al., 2017; Wilkes et al., 2017).

Recent forestry related applications with UAV-LS cover Digital Elevation Model (DEM) generation (Wei et al., 2017), Canopy Height Model (CHM) generation, Leaf Area Index (LAI) estimation, AGB estimation via allometric equations based on tree height and crown area (Guo et al., 2017), Diameter at Breast Height (DBH) estimation (Brede et al., 2017; Wieser et al., 2017), tree height estimation and localisation (Wallace et al., 2014b), and tree detection and segmentation (Wallace et al., 2014a; Balsi et al., 2018). With these UAV-LS systems available now, the question can be investigated how UAV-LS point clouds compare to TLS point clouds for explicit structural tree modelling.

The aim of this study was to compare tree volume estimation performance of high density UAV-LS (>1000 points $/ \mathrm{m}^{2}$ ) with TLS point clouds for different canopy architectures, 
including deciduous and coniferous species. Tree volume was investigated instead of AGB, because AGB is a product of tree volume and wood density, the latter being equal for both laser scanning systems. The work flow strongly builds on established TLS methods. This will make fast tree volume estimation possible at the plot scale, and support calibration and validation of future AGB missions at hectometric scale.

\section{Data}

\subsection{Study Site}

This study was performed at the Speulderbos Reference site in the Veluwe forest area (N52 $15.15^{\prime}$ E5 $42.00^{\prime}$ ), The Netherlands (Brede et al. 2016, www . wur . eu/fbprv). Five stands were scanned on May 10, 2017 (Figure 1, Table 1). The first and in terms of area largest consisted of maturing European beech (Fagus sylvatica) and oak (Quercus robur, Q. petraea), here referred to as old beech and oak. Crown heights of sampled trees reached up to $32 \mathrm{~m}$, but were $27 \mathrm{~m}$ on average. During the data acquisitions, leaves were only emerging or not present on these trees. The understorey was sparse with only few seedlings and young trees, and occasional European holly (Ilex aquifolium). A forest road separated this beech and oak stand from the second stand consisting of young beech with trees of on average $23 \mathrm{~m}$ height. These beeches were markedly different from the old beech stand in terms of age and consequently stem diameter (Table 1). Additionally, their branching behaviour was less complex with most tree volume concentrated in the central trunk. In contrast to this, the old beech trees showed more complex structure with major branching occasionally occurring below $10 \mathrm{~m}$ height. In addition, the young beech trees almost all carried new leaves.

Located north of the young beech stand was the third stand consisting of Norway spruce (Picea abies) with maximum tree height of $25 \mathrm{~m}$. Located further east was the fourth stand, a Giant fir (Abies grandis) stand with maximum heights of $27 \mathrm{~m}$. Both Norway spruce and Giant fir trees were characterised by numerous small branches along the main stem.

The fifth stand was in the South-East of the study area and consisted of Douglas fir (Pseudotsuga menziesii) with maximum tree heights of $35 \mathrm{~m}$, making up the highest trees in 
Table 1: Stand sample characteristics. Tree density was estimated based on manually identified trees in the TLS point cloud, tree height based on segmented tress range in height, and DBH based on optimised TLS Quantitative Structure Models (QSMs).

\begin{tabular}{lccccc}
\hline & $\begin{array}{c}\text { Giant } \\
\text { fir }\end{array}$ & $\begin{array}{c}\text { Norway } \\
\text { spruce }\end{array}$ & $\begin{array}{c}\text { Douglas } \\
\text { fir }\end{array}$ & $\begin{array}{c}\text { Young } \\
\text { beech }\end{array}$ & $\begin{array}{c}\text { Old beech } \\
\text { \& oak }\end{array}$ \\
\hline Tree density $\left(\right.$ ha $\left.^{-1}\right)$ & 588 & 714 & 231 & 554 & 142 \\
Minimum tree height $(\mathrm{m})$ & 11.3 & 14.6 & 18.7 & 4.6 & 18.4 \\
Average tree height $(\mathrm{m})$ & 21.1 & 19.9 & 30.6 & 16.4 & 27.2 \\
Maximum tree height $(\mathrm{m})$ & 27.4 & 25.1 & 35.3 & 22.5 & 31.6 \\
Minimum DBH $(\mathrm{cm})$ & 11.2 & 14.4 & 15.6 & 6.2 & 22.9 \\
Average DBH $(\mathrm{cm})$ & 28.5 & 28.5 & 40.1 & 21.3 & 59.2 \\
Maximum DBH $(\mathrm{cm})$ & 58.4 & 46.9 & 56.5 & 37.1 & 91.0 \\
\hline
\end{tabular}

the study area. This stand had only little understorey, and had been thinned in recent years as could be recognised by tractor tracks and stumps. Additionally, the lower tree trunks were mostly free of branches.

\section{2. $U A V-L S$ Data}

UAV-LS data were collected with a RIEGL RiCOPTER with VUX-1UAV (RIEGL Laser Measurement Systems GmbH, Horn, Austria). The VUX-1UAV is a survey-grade laser scanner with an across-track Field Of View (FOV) of $330^{\circ}$ (Table 2). UAV-LS data acquisition were conducted in the course of 2 hours (Brede et al., 2017). The take-off site was chosen in the western part of the study area in a clearing, which allowed operation within Visual Line of Sight (VLOS). The study area of $100 \mathrm{~m}$ x $180 \mathrm{~m}$ was covered with a total of 8 parallel flight lines (Figure 1) and one diagonal cross-line at an altitude of $90 \mathrm{~m}$ above ground.

The collected raw data were processed with the VUX-1UAV accompanying software package RiPROCESS. This included (i) post-processing of the Global Navigation Satellite System (GNSS) and Inertial Measurement Unit (IMU) records to reconstruct the flight 


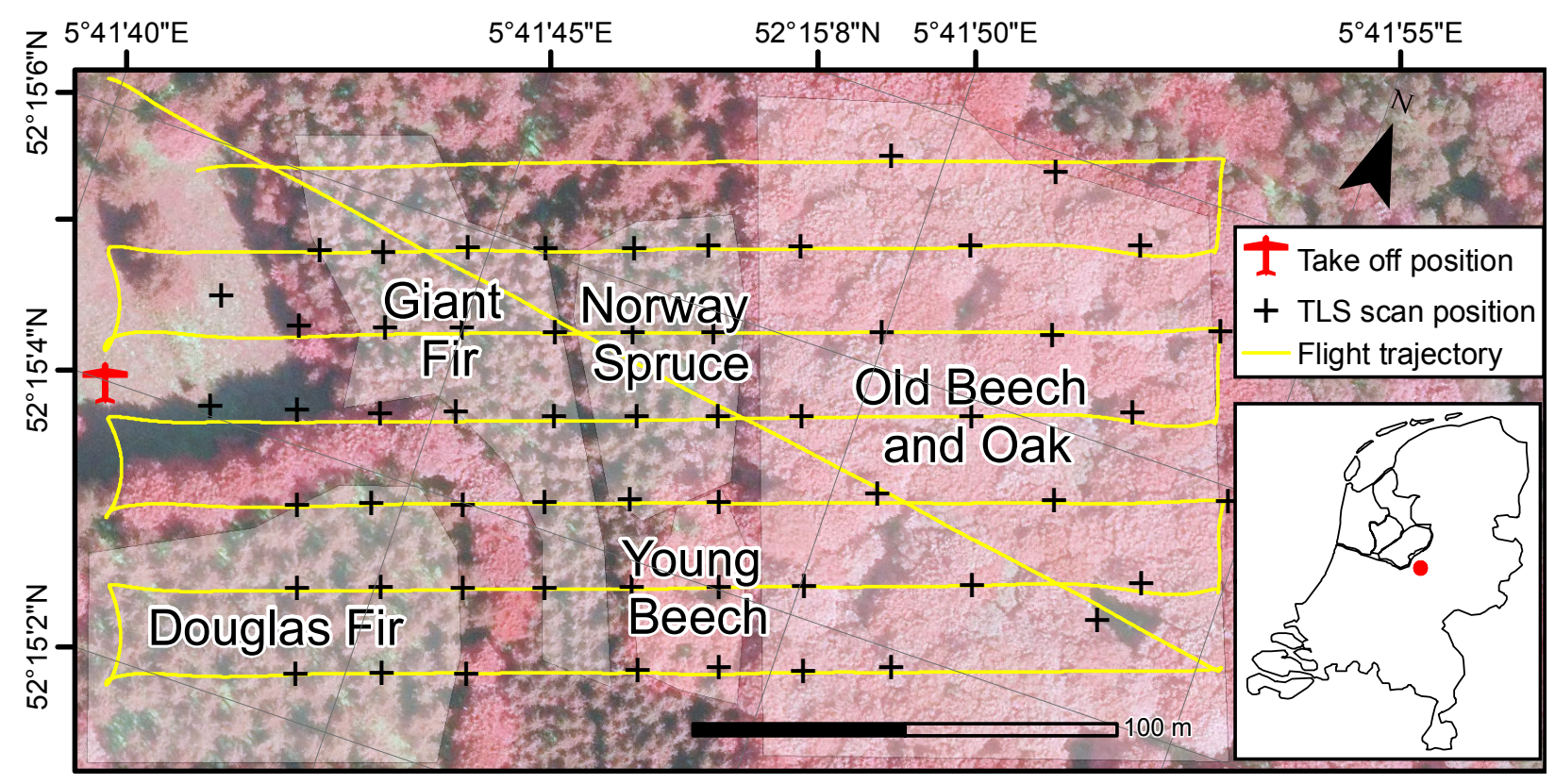

(a) Map of the study site with stand locations, TLS scan positions and UAV-LS flight trajectory. Location within the Netherlands marked as red dot on inset map.

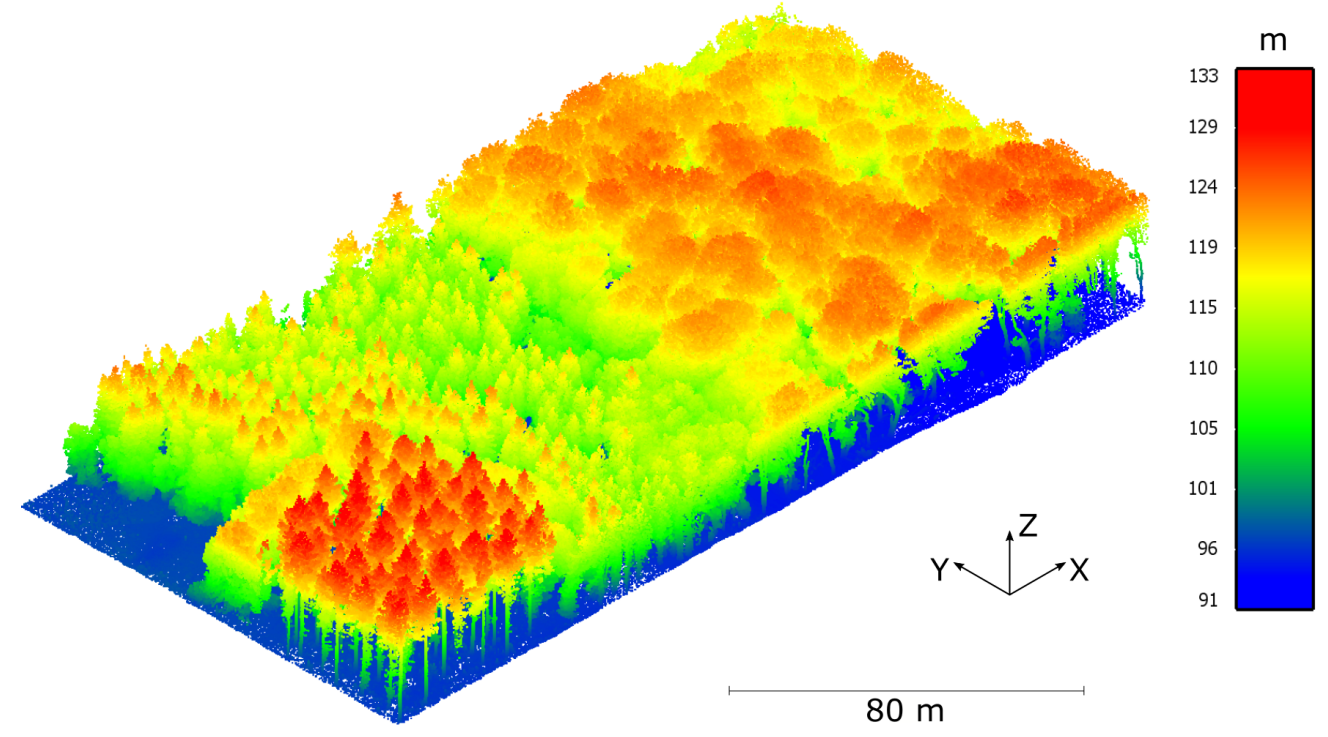

(b) Perspective view on the study site based on UAV-LS point cloud. Colour represents height (in project coordinate system) with colour scale on right in meters. Trihedron shows project coordinate system axis direction.

Figure 1: Study site views in map and perspective view. 
Table 2: VZ-400 and VUX ${ }^{\circledR}-1 \mathrm{UAV}$ main characteristics

\begin{tabular}{lrr}
\hline Characteristic & VZ-400 & VUX-1UAV $^{2}$ \\
\hline Maximum Pulse Repition Rate (PRR) (kHz) & 300 & 550 \\
Maximum effective measurement rate (kHz) & 120 & 500 \\
Minimum / Maximum range (m) & $1.5 / 350^{3}$ & $3 / 920^{4}$ \\
Accuracy / Precision (mm) & $5 / 3$ & $10 / 5$ \\
Laser wavelength (nm) & 1550 & 1550 \\
Beam divergence (mrad) & 0.35 & 0.5 \\
Weight $(\mathrm{kg})^{5}$ & 9.6 & 3.75 \\
\hline${ }^{1}$ high speed mode, incl. online waveform processing \\
${ }^{2} 550 \mathrm{kHz}$ mode ${ }^{3}$ at target $\rho \geq 0.9{ }^{4}$ at target $\rho \geq 0.6$ \\
${ }^{5}{ }^{5}$ without battery and tilt mount
\end{tabular}

trajectory, (ii) LIght Detection And Ranging (LiDAR) waveform analysis for target detection in scanner geometry and (iii) translation of the detected points into global coordinate system under consideration of the trajectory information. Additionally, single flight geometry was optimised with automatically detected control-planes in the point cloud. Finally, all flight lines were manually fine-registered based on 12 ground control targets, which were placed throughout the study area. A detailed description of the acquisition and processing work-flow is described in Brede et al. (2017). The resulting UAV-LS point cloud had densities between 2965 and 5344 points $/ \mathrm{m}^{2}$ depending on the position of the flight lines and tree heights with an average of 4059 points $/ \mathrm{m}^{2}$.

\subsection{TLS Data}

TLS data were collected with a RIEGL VZ-400 scanner from 58 scan positions during two days (Table 2). This scanner was used in several studies dealing with explicit, threedimensional tree modelling (Lau et al., 2018) and AGB estimation (Calders et al., 2015b; Gonzalez de Tanago et al., 2018). The scan positions were spaced on a $20 \mathrm{~m}$ grid across the study area, but with slightly wider spacing in the old beech and oak stand due to good 
visibility (Figure 1). The angular scan resolution was set to $0.06^{\circ}$. Due to the limitation of the VZ-400 to a minimum viewing zenith angle of $30^{\circ}$, a second scan was performed at each position with a $90^{\circ}$ tilted scanner to capture the canopy directly above the scan position. Five to ten retro-reflective targets were placed in between scan positions to facilitate co-registration following row pattern described by Wilkes et al. (2017). Fine-registration between positions was achieved with RIEGL's multi-station adjustment routine built into the RiSCAN PRO software (Wilkes et al., 2017). This automatically searches for planar surfaces in the point clouds and uses them for co-registration between the point clouds. The fitting residual standard deviation was $0.62 \mathrm{~cm}$. The final TLS point cloud was co-registered to the UAV-LS point cloud with the help of five Ground Control Points (GCPs) distributed over the study area.

\section{Methods}

The work-flow consisted of mixed manual and automatic steps and an overview is given in Figure 2. All manual steps combined took approximately 20 to $40 \mathrm{~min}$ per tree sample. The principal steps included identification and segmentation of single trees from the overall point clouds (Segmentation steps in Figure 2, Section 3.1), filtering foliage and normalising point cloud density in preparation for 3D modelling (Filtering/Normalisation steps, Section 3.2), fitting explicit, geometric 3D models with the TreeQSM routine (QSM modelling steps, Section 3.3), optimising TreeQSM parameter selection (Section 3.4) as well as intercomparison of UAV-LS and TLS models (Section 3.5). TreeQSM is a method that builds explicit tree models from laser scanner point clouds based on single tree point clouds by first identifying tree elements like trunks and branches, and then fitting cylinders to them (Raumonen et al., 2013).

\subsection{Tree Segmentation}

In recent years, several automatic tree segmentation algorithms for ALS have been proposed (Duncanson et al., 2014; Heinzel and Huber, 2016; Parkan and Tuia, 2018). However, understorey trees are usually hard to detect (Eysn et al., 2015). Also, methods based on 


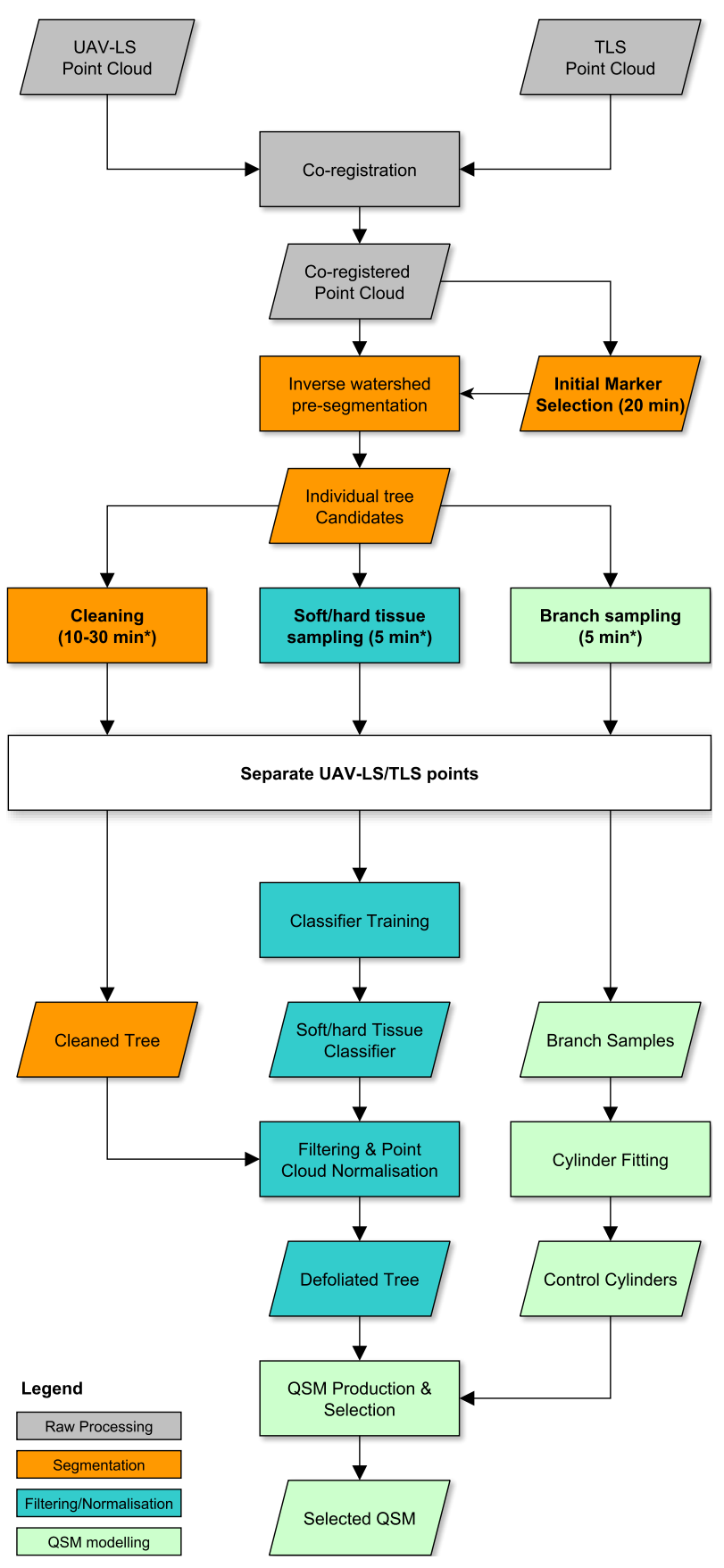

Figure 2: Processing work-flow for individual tree volume estimation based on UAV-LS and TLS point clouds. Steps with time specifications indicate needed time required for manual work. Steps with an asterisk are per sampled tree. As indicated, manual steps on the tree sample were performed for combined UAV-LS and TLS point clouds. Later, the combined point clouds were separated again based on a dedicated point cloud attribute. 
the CHM potentially separate elements from trees especially when crowns are inter-locked. This was particularly the case with the old beech and oak stand. As tree segmentation in this study needed to be of best quality to leave tree architecture in place, a semi-automatic procedure was chosen that took advantage of both UAV-LS and TLS datasets.

The segmentation was essentially a marker-based inverse watershed segmentation (Koch et al., 2006) followed by manual correction. The co-registration allowed to segment the UAV-LS and TLS point clouds together. Tree trunks were manually identified to serve as initial markers with Quantum GIS 2.18 (QGIS Development Team, https://qgis.org) based on $0.2 \mathrm{~m}$ resolution TLS point density maps. The tree trunks were clearly visible in this map as they were hit often and cover only a small ground area compared to upper branches and crowns. A $0.2 \mathrm{~m}$ resolution CHM was derived as the difference between DEM and Digital Surface Model (DSM) based on the UAV-LS point cloud (Brede et al., 2017). Then, the inverse watershed segmentation implemented in the R ForestTools package (https://cran.r-project.org/web/packages/ForestTools/) was applied based on the TLS markers and UAV-LS CHM. Only crowns with a height of at least $5 \mathrm{~m}$ were considered for the automatic segmentation. The single segments were exported for inspection. UAV-LS and TLS points were exported together, but marked with different labels for later filtering. From the range of automatically segmented trees, sample trees for later modelling were manually selected. The selection was aiming to sample trees from across different locations within the stands (Figure 1) to cover the different levels of point densities produced by the flight pattern, as well as tree size indicated by the trunk and crown size in order to maximise the range of sizes to evaluate tree volume modelling with small and large trees. Next, the single tree point clouds were manually inspected and points not belonging to the specific tree were removed. In some cases, neighbouring trees had to be inspected together to transfer significant branch points from one to the other. Also, tree and branch identification was much easier with the TLS than with the UAV-LS point clouds. Additionally, points representing ground were removed. Finally, UAV-LS and TLS points were separated based on their labels. All manual work was performed by the same operator to assure comparable quality over all 
the selected trees. CloudCompare 2.10 was used in this analysis (http://cloudcompare.org) to perform the $3 \mathrm{D}$ work.

\subsection{Point Cloud Foliage Filtering and Density Normalisation}

In the next step, the point clouds were filtered and normalised. During the filtering foliage was removed, as this was not focus of this study. Also, foliage is not modelled with TreeQSM and can only be recognised by the routine to a limited extent. Filtering was especially important for the coniferous species in the study area, but also some of the deciduous trees already showed young leaves. Density normalisation is a necessary step prior to 3D model fitting, as the model routines assume equal density of the point clouds across the tree. In this study, this assumption was particularly violated by the UAV-LS data with a much higher number of hits in the upper crown (Brede et al., 2017).

Foliage filtering was based on a supervised Random Forest classification (Breiman, 2001; Belgiu and Drăgu, 2016; Zhu et al., 2018). For this, training samples representing hard (trunk, branches) and soft (leaves) tissue were manually selected from the tree point clouds. Based on the radiometric properties of these points, individual models were trained for each stand, and separately for UAV-LS and TLS, resulting in a total of 10 models. Radiometric features were apparent reflectance, RIEGL deviation number - a measure of pulse waveform deviation from the expected shape (Calders et al., 2017) - and return characteristic (i.e., first, intermediate, last return). Other studies proposed to involve additional geometric features such as local neighbourhood relationships to improve classification results (Wang et al., 2018; Zhu et al., 2018). However, classification accuracy based solely on radiometric features was considered sufficient for hard tissue candidate selection in this study as these already provided good classification results.

For each Random Forest model, 2000 samples were picked for both soft and hard tissue for training. Model performance was checked with a 5-fold cross-validation. The final models were trained on all 4000 samples to produce the class probability rather than the class. In the filtering step, only points with a hard tissue probability of more than $90 \%$ were selected for each tree. During the density normalisation the class probability was utilised as a selection 
criterion. The points were segmented into voxels and within each voxel the point with the highest hard tissue probability was selected. The grid size for TLS was $2.5 \mathrm{~cm}$, which closely follows Calders et al. (2018) and recommendations by Wilkes et al. (2017). The UAV-LS grid size was set to $10 \mathrm{~cm}$, which is in line with the lower density of the UAV-LS point clouds.

\subsection{Tree Modelling with TreeQSM}

Explicit 3D cylinder models of trees were produced with TreeQSM in this study. TreeQSM was introduced as a way to effectively fit cylinder models to detailed TLS point clouds, taking into account tree inherent structure like connectivity, branching and branch tapering (Raumonen et al. 2013, https://github.com/InverseTampere/TreeQSM). Additionally, TreeQSM neither makes assumptions based on tree species nor distinguishes between deciduous and coniferous tree architectures. TreeQSM was used in several studies to automatically produce 3D tree models, and estimate tree volume and subsequently AGB (Calders et al., 2015b; Gonzalez de Tanago et al., 2018).

The TreeQSM fitting procedure is extensively explained in Raumonen et al. (2013), Calders et al. (2015b) and Gonzalez de Tanago et al. (2018). Essentially, tree modelling is performed in two main steps. First, the point cloud is segmented into trunk and individual branches. The segmentation uses small subsets or patches in two phases. In the first phase large constant size patches with radius Patch Diameter 1 (PD1) are used across the tree. This segmentation serves to identify the tree's coarse architecture and branches. Second, a finer cover with patch size varying from Patch Diameter 2 (min) (PD2Min) to Patch Diameter 2 ( $\max )(\mathrm{PD} 2 \mathrm{Max})$ determines the final branch topology. Finally, individual branch elements are reconstructed by least squares fitting of cylinders.

PD2Min plays a central role in the TreeQSM tuning, as it defines the smallest possible features that will be modelled. Hence, it has to be adapted to the smallest features that can be resolved with the data available. Additionally, there is a random component in the initialisation of the patches. This makes it necessary to run the same parameter settings multiple times for each tree and aggregate the produced models, which provides a measure of modelling confidence. 
In this study, parameters were chosen based on experience from previous studies (Calders et al., 2015b; Gonzalez de Tanago et al., 2018; Lau et al., 2018), while parameters for UAV-LS parameters were adapted in accordance with the UAV-LS lower point density. PD1 was kept constant for all trees. In the case of UAV-LS and TLS, it was chosen as 20 and $18 \mathrm{~cm}$, respectively. PD2Min was varied from 2 to $31 \mathrm{~cm}$ in steps of $2 \mathrm{~cm}$ for UAV-LS and 2 to $11 \mathrm{~cm}$ in steps of $0.5 \mathrm{~cm}$ for TLS. PD2Max was varied from 10 to $70 \mathrm{~cm}$ in steps of $10 \mathrm{~cm}$ for UAV-LS and between 10 to $14 \mathrm{~cm}$ for TLS. The variation was conducted in a full-grid approach and each parameter combination was run 10 times, to derive statistics about the modelling uncertainty of the respective parameter set.

\subsection{Best Fit QSM Identification}

Although TreeQSM produces inherently valid models with respect to topology and tapering for a range of input parameters, the best fitting model for a given point cloud has to be identified independently. Calders et al. (2015a) proposed an automatic framework for parameter tuning that was successfully applied to TLS data in Calders et al. (2015b) and Calders et al. (2018). This framework is based on selecting segments along the trunk and fitting circles to each via least squares optimisation. These circles provide a robust measure of the trunk diameter at the respective height. Then, the QSM is selected that matches the circle radii best. This procedure has the advantage that the circles deliver measures of the trunk that are independent from the QSM. However, in a previous study circle fitting at DBH height for 19 out of 58 trees (33\%) was unsuccessful for the dataset used in this study due to too low point density (Brede et al., 2017).

Therefore, the procedure of Calders et al. (2015a) was adapted to use cylinders instead, which are the extension of circles into the third dimension. This has the advantage to take more space and potentially more points into account, thereby overcoming the problem of low point density at specific positions at the trunk for the UAV-LS data. For the purpose of cylinder fitting, three to six straight parts of the trunk or big branches were manually selected from each tree. The parts had to contain at least 10 returns to be taken into consideration for cylinder fitting. Cylinders were fitted in two steps: first, the orientation of each cylinder 
was estimated based on point normals and Hough transformation (Rabbani and Heuvel, 2005). Then, the points were projected onto the plane that was orthogonal to the cylinder central axis. This allowed to estimate radius and central axis with least squares circle fitting.

Based on the radii of these derived control cylinders the tuning followed the framework of Calders et al. (2015a) per tree, and independently for UAV-LS and TLS. For all QSMs, the QSM cylinders that were closest to the control cylinder centres were identified. The maximum allowed angle and distance between QSM and control cylinder were $15^{\circ}$ and $50 \mathrm{~cm}$, respectively. Per TreeQSM parameter combination, the QSM model cylinder radii $r_{Q S M}$ were related to the control cylinder radii $r_{\text {control }}: \Delta r=1-\left(r_{\text {control }}-r_{Q S M}\right) / r_{\text {control }}$. The absolute average over all control cylinders was defined as $c_{\text {match }}$. Subsequently, the mean $\overline{c_{\text {match }}}$, standard deviation $\sigma_{c}$ and coefficient of variation $C V_{c}$ were derived. Then the parameter combination with the largest PD2Min was chosen where $C V_{c}<C V_{\text {threshold }}$ and $\overline{c_{\text {match }}}>c_{\text {conformity }}$, where $c_{\text {conformity }}=5 \times \min \left(C V_{c}\right)$ and $c_{\text {conformity }}=0.95$. If no such parameter set existed, the parameter set with the lowest $C V_{c}$ was selected. If no control cylinders could be derived from the segments, the model with the parameter set with the lowest standard deviation in volume was chosen.

\subsection{QSM Comparison}

For the assessment of UAV-LS correspondence to TLS QSMs total volume across samples in a stand, Concordance Correlation Coefficient (CCC) - a measure for the agreement of two methods measuring the same quantity (Lin, 1989) — was used. The CCC is a measure of the orthogonal distance of the two methods from the 1:1 line through. An advantage of the CCC over Pearson's correlation coefficient is its ability to detect offset and gain shifts of the measures. It is computed as:

$$
C C C=\frac{2 \rho \sigma_{12}}{\sigma_{1}^{2}+\sigma_{2}^{2}+\left(\mu_{1}-\mu_{2}\right)^{2}}
$$

where $\rho$ is the correlation coefficient of the two measures, and $\sigma^{2}$ and $\mu$ are the corresponding variances and means, respectively. 
RMSE was used to quantify the magnitude of the deviation of modelled volume and Mean Signed Difference (MSD) to assess the bias. The averaged Coefficient of Variation (CV) across samples of a stand gave an indication of the model uncertainty.

In order to get further insights into how the estimated volume was distributed over the vertical dimension of QSMs, vertical volume distribution profiles were computed. For this, volume was summed up across 30 height layers relative to the maximum height and to the total volume of each individual tree. The height layers were defined by the minimum and maximum height coordinate of each segmented TLS tree point cloud. This allowed comparison across all trees within the same stand as well as across stands.

\section{Results}

\subsection{Tree Segmentation}

The CHM was segmented based on 767 manually selected markers (Figure 3). Some of the sampled tree point clouds also included additional non-dominant understorey trees, especially in the old beech and oak stand. These trees were also considered for the further processing. In total, 40 trees per stand were selected, summing up to a total of 200 .

\subsection{Foliage Filtering}

Table 3 summarises the foliage identification performance for the UAV-LS and TLS point clouds. All models achieved classification accuracies $\geq 0.71$, while all except UAV-LS in the Norway spruce stand and in the young beech stand achieved accuracies $\geq 0.91$. The Norway spruce trees seemed to provide challenges due to their high number of small branches close to the trunks, which resulted in only few trunk returns. These were prone to be higher order returns, which could lead to degradation in the reflectance signal in the selected training data. In the case of the young beech trees, the trunks were small in diameter even though they were more sparsely covered by branches than for example the Norway spruce. However, the small trunk surfaces might have led to partial returns at the trunk edges, which also could have effects on the reflectance signal. Nonetheless, classification accuracy was generally high, and UAV-LS and TLS showed comparable results. 


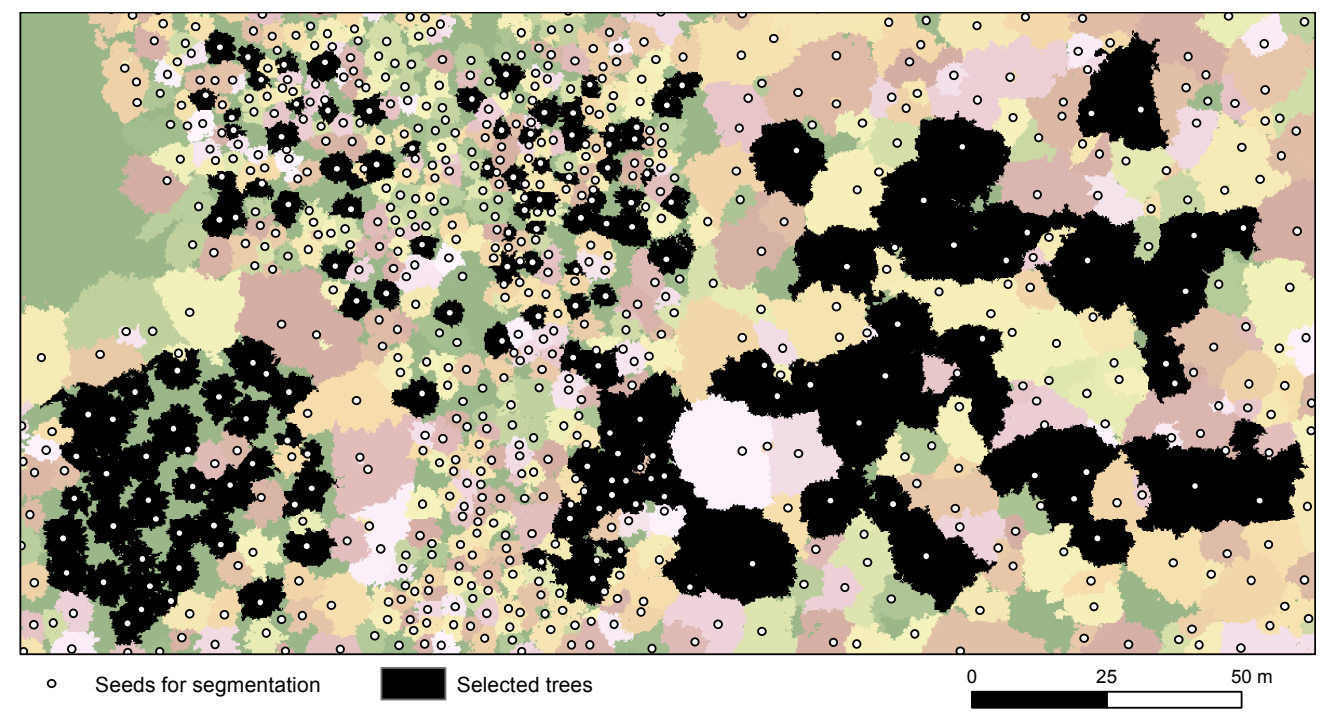

Figure 3: Manually selected seeds for watershed segmentation, segmented CHM and selected trees for 3D modelling in project coordinate system. Some selected segments contained more than one tree and some contained none.

Table 3: Classification performance for point cloud filtering from 5-fold cross-validation.

\begin{tabular}{lrr}
\hline Stand & Accuracy UAV-LS & Accuracy TLS \\
\hline Douglas fir & 0.96 & 0.95 \\
Giant fir & 0.91 & 0.95 \\
Norway spruce & 0.71 & 0.93 \\
Old beech and oak & 0.94 & 0.92 \\
Young beech & 0.82 & 0.88 \\
\hline
\end{tabular}




\subsection{Control Cylinders}

Cylinder fitting was successful for at least one cylinder for all TLS-based tree point clouds and in 185 out of 200 cases $(92.5 \%)$ for the UAV-LS. Figure 4 summarises the estimated cylinder diameters compared with TLS. Generally, cylinders could be fitted best for the old beech and oak trees with CCC of 0.99 and RMSE of $2.3 \mathrm{~cm}$ in diameter. Foliage was least developed in this stand, exposing trunks, so that they could be sampled well from above.

Giant fir and Norway spruce control cylinders were estimated about equally with CCC of 0.96 and 0.93 , and RMSE of 2.38 and $2.26 \mathrm{~cm}$, respectively. However, for $6(15 \%)$ and $5(12.5 \%)$ trees no control cylinders could be successfully fitted, respectively. The foliage and small branches of these species shielded their trunks, which made already the cylinder selection in the TLS point cloud difficult during manual segmentation.

In the case of young beech trees, four individuals could not produce acceptable control cylinders. UAV-LS fitting performance compared to TLS was lower with CCC of 0.88 and RMSE of $3.69 \mathrm{~cm}$ when compared to the old beech trees. The young beech stand was relatively open, but tree diameters were small, so that the chance of trunk hits was much lower than for larger trees. Additionally, UAV-LS estimated cylinders were on average $1.18 \mathrm{~cm}$ larger compared to TLS. This was due to cylinders only partially covered with points.

The effect of partial coverage was even stronger in the Douglas fir stand due to its position in the corner of the stand. This position prevented good visibility of the trunks from the last diagonally crossing flight line (Figure 1). In combination with the relatively large trunks this led to the largest RMSE of all stands of $7.90 \mathrm{~cm}$ and on average $4.71 \mathrm{~cm}$ larger cylinder diameters compared to TLS.

\subsection{QSM Comparison}

Figure 5 and 6 compare acquired (segmented) point clouds, normalised point clouds and QSM samples for the largest beech tree found in the study area and a Douglas fir, respectively. In both cases, UAV-LS delivered sufficient points to visually delineate the lower part of the trunk, i.e., the volume of the trunk could be delineated clearly on all sides. The normalisation with foliage filtering typically removed a significant part of points, especially 

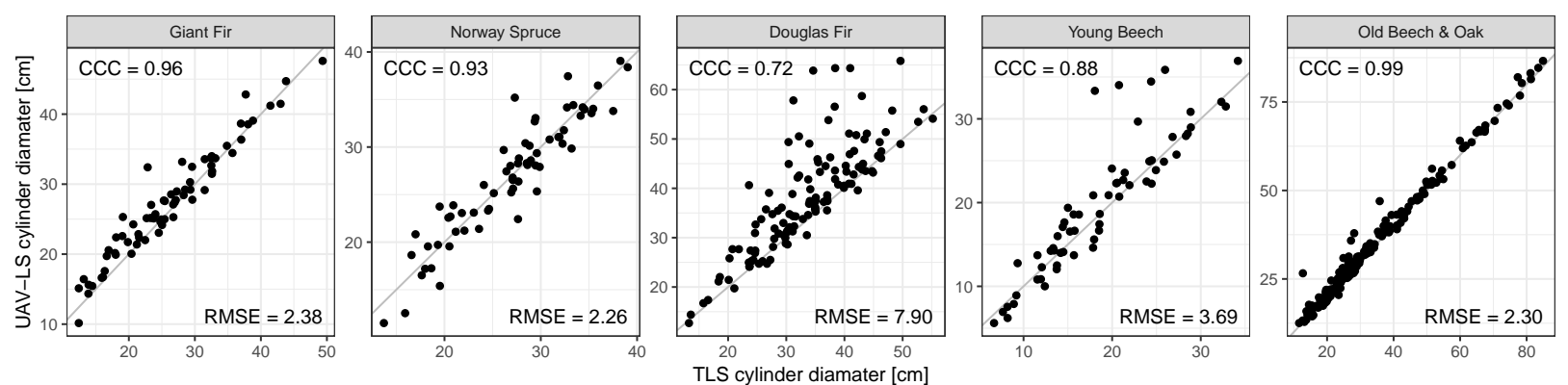

Figure 4: UAV-LS estimated cylinder diameter compared to TLS. Grey lines are 1:1.

in the upper crown area. For TLS, this were $92.7 \%$ and $94.9 \%$ of the points in case of the beech and the Douglas fir, respectively. For UAV-LS, $77.6 \%$ and $88.8 \%$ of the points were removed, respectively. However, the identification of foliage in the UAV-LS point clouds seemed to be less effective, despite high cross-validation classification accuracy between 0.71 and 0.96 (Table 3). Also, the UAV-LS normalised point clouds did not show upper branches as clearly, compared to the TLS normalised point cloud. This means branches could be recognised, but only after careful checking and turning of the point cloud. Also, some branch surfaces were not sampled completely, so that guessing the occupied volume visually was more difficult. A consequence of this incompleteness is that the QSM derived from UAV-LS resulted in a much less coherent upper crown modelling: cylinders did not follow natural growth directions and a much higher number of cylinders was fitted than seemed necessary, when compared to TLS.

Considering all sampled trees, UAV-LS tree volume estimation in comparison to TLS volume varied markedly across the different stands in the study area (Figure 7). As was the case in the control cylinder diameter estimation (Section 4.3), UAV-LS based old beech and oak QSMs showed overall the closest correspondence to TLS based QSMs in terms of volume with CCC of 0.51 . Additionally, the modelling uncertainty expressed as mean CV was lowest among all stands with a value of 0.10 . The structural characteristics of this stand were probably the most favourable for UAV-LS sampling of all the considered stands. The relatively wide spacing between individuals, the large trunks with reconstructed DBH of up to $91.0 \mathrm{~cm}$ and the comparably low shielding of lower canopy elements by upper branches and 


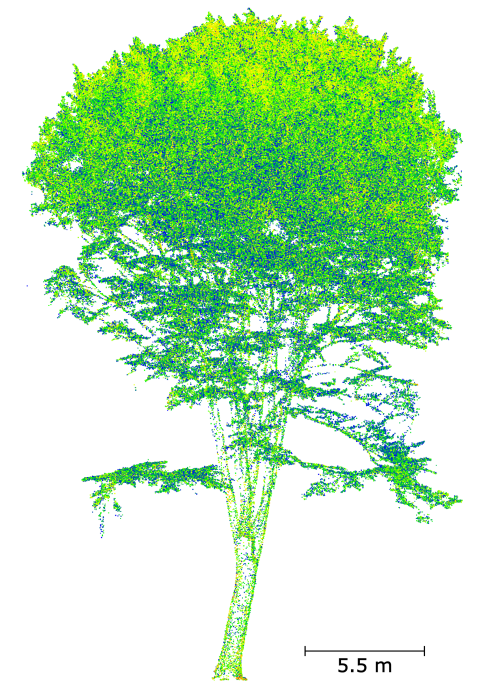

(a) Segmented UAV-LS

$(\mathrm{P}=1088317)$

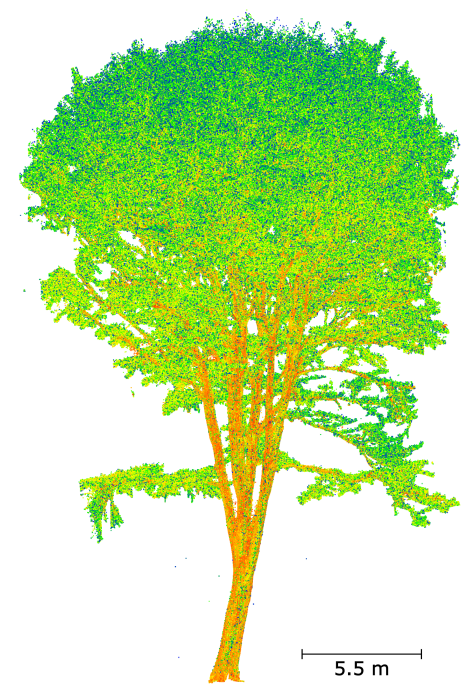

(d) Segmented TLS

( $\mathrm{P}=4626368)$

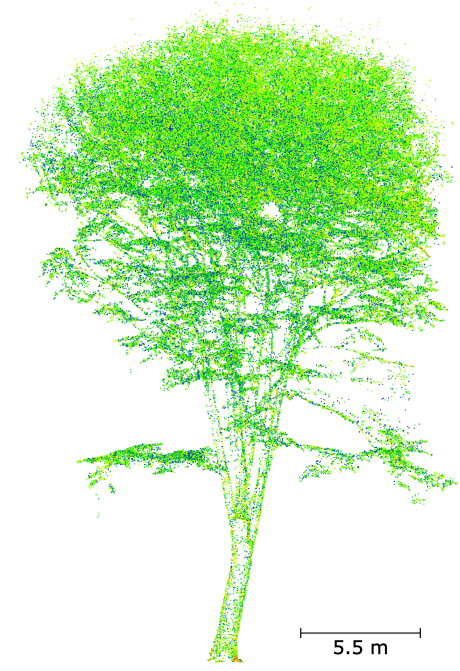

(b) UAV-LS normalised

$(\mathrm{P}=243680)$

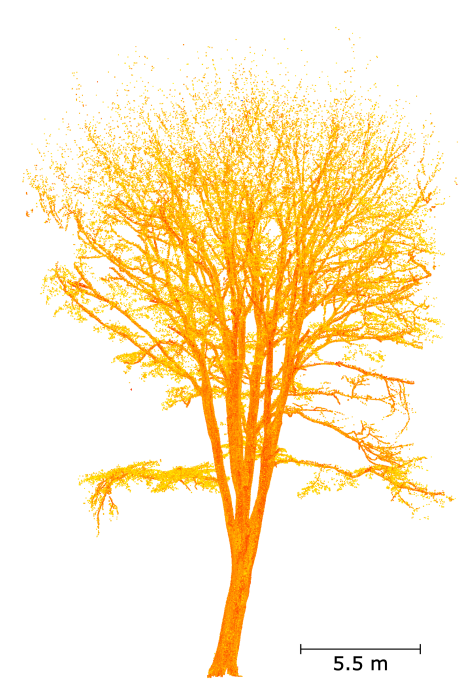

(e) TLS normalised

$(\mathrm{P}=337326)$

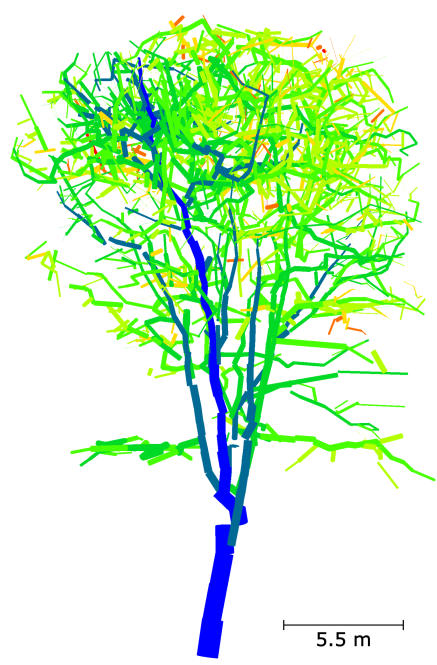

(c) UAV-LS QSM

$(\mathrm{C}=2464)$

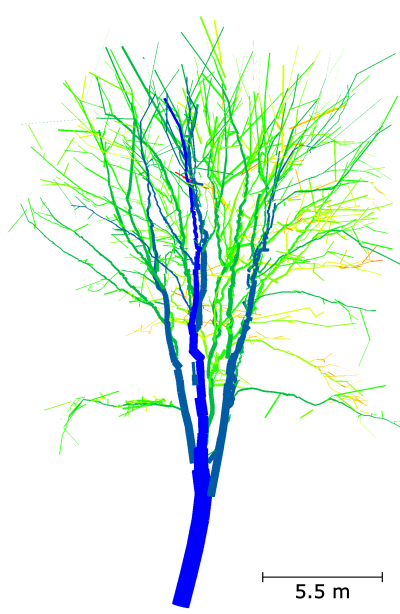

(f) TLS QSM

(C = 3471)

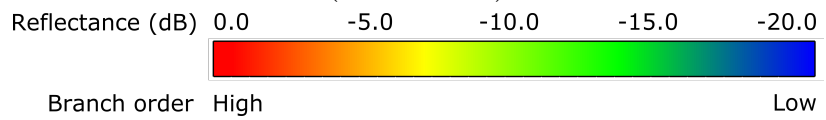

Figure 5: Tree segmentation, point density normalisation and QSM example for beech. Point cloud colour represents reflectance, QSM colour refers to branching order (maximum 7 for UAV-LS and 8 for TLS) (see scale). Number of points $\mathrm{P}$ or cylinders $\mathrm{C}$ in caption. 


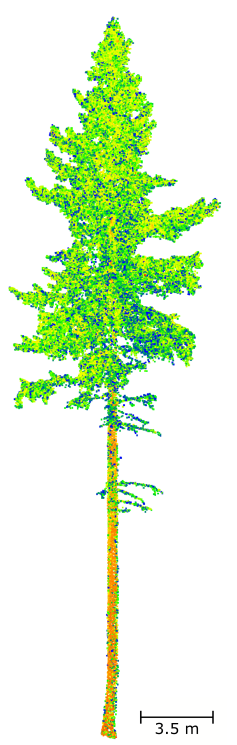

(a) Segmented UAV-LS

$(\mathrm{P}=197484)$

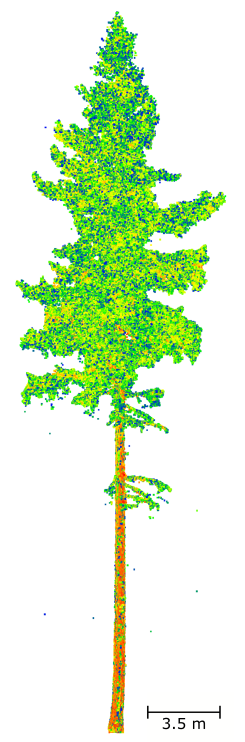

(d) Segmented TLS

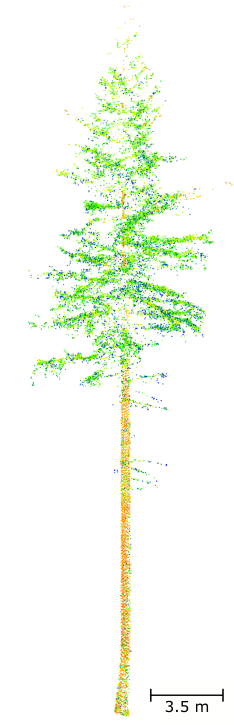

(b) UAV-LS normalised

( $\mathrm{P}=22$ 012)

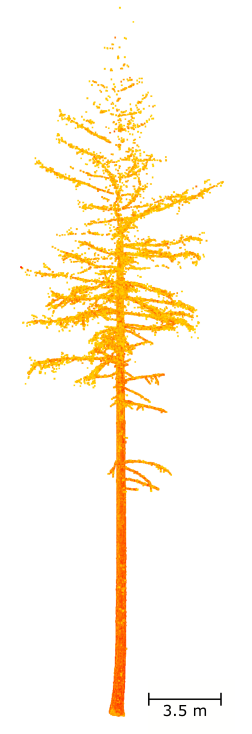

(e) TLS normalised

$(\mathrm{P}=81888)$

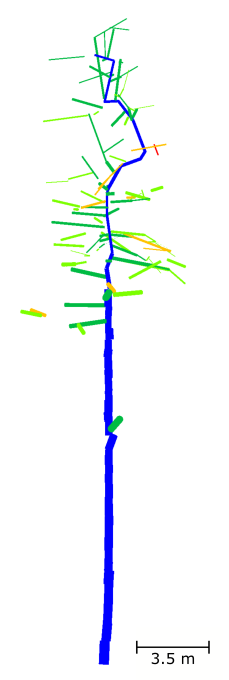

(c) UAV-LS QSM

$(\mathrm{C}=141)$

$(\mathrm{P}=1613021)$

Reflectance (dB) 0.0 $-5.0$ $-10.0$

Branch order High

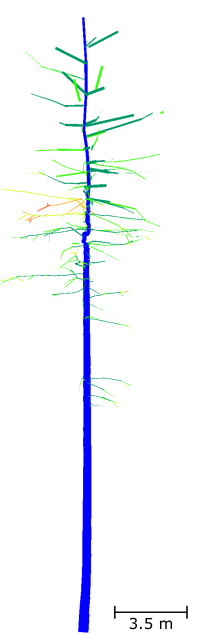

(f) TLS QSM $(\mathrm{C}=588)$

Figure 6: Same as Figure 5, but for a Douglas fir. Maximum branching orders 4 for UAV-LS and 5 for TLS. 
foliage when seen from above had a positive effect on volume estimation. However, UAV-LS volume estimates for large specimen in this stand were positively biased as indicated by the MSD of $3.44 \mathrm{~m}^{3}$. This bias in combination with the fact that the old beech and oak stand contained the largest trees in the study area produced the largest RMSE among all stands of $6.59 \mathrm{~m}^{3}$. Inspecting the distribution of the volume over differently sized cylinders gave further insights how this could be traced to differently sized branches (Figure 9): Considering only large cylinders with diameter $\geq 30 \mathrm{~cm}$ resulted in high correspondence between UAV-LS and TLS with CCC $>0.85$, RMSE as low as $0.65 \mathrm{~m}^{3}$ and MSD as low as $0.1 \mathrm{~m}^{3}$. But taking smaller cylinders into account, considerably degraded UAV-LS volume estimates for this stand in terms of all performance metrics. CCC of minimum 0.42, and RMSE and MSD of maximum 6.70 and $3.57 \mathrm{~m}^{3}$, respectively, were reached. Furthermore, it was possible to trace the differences between UAV-LS and TLS volume estimates to the vertical distribution of cylinder volume (Figure 8). It could be seen that UAV-LS overestimated volume in the upper half of trees with an average contribution of this part of $41.3 \%$ to the total tree volume for UAV-LS compared to $27.6 \%$ for TLS. The reason for this could be observed in the sample (Figure 5), but also in all other old beech and oak trees' QSMs. The upper crown was modelled as a large number of small cylinders that were apparently not corresponding to real branches. Probably the quality of the point clouds was not sufficient in terms of point count and point registration accuracy.

Apart from these general observations for the old beech and oak stand, an outlier could be observed when only considering large cylinders (Figure 9). This specimen was located at the southern edge of study area. Inspecting the point cloud together with QSM realisations revealed that the stem was not modelled with cylinders as large as those of the TLS QSM, but with many smaller cylinders. The UAV-LS point cloud mainly contained points from one side of the tree and trunk, which were not sufficient to model the whole circumference. The most southern UAV-LS flight line was nearly directly over this tree effectively preventing registration of points on the southern trunk sites. The corresponding UAV-LS point cloud covered only the trunk surfaces facing into the stand, which resulted in a QSM with undersized trunk cylinders. 

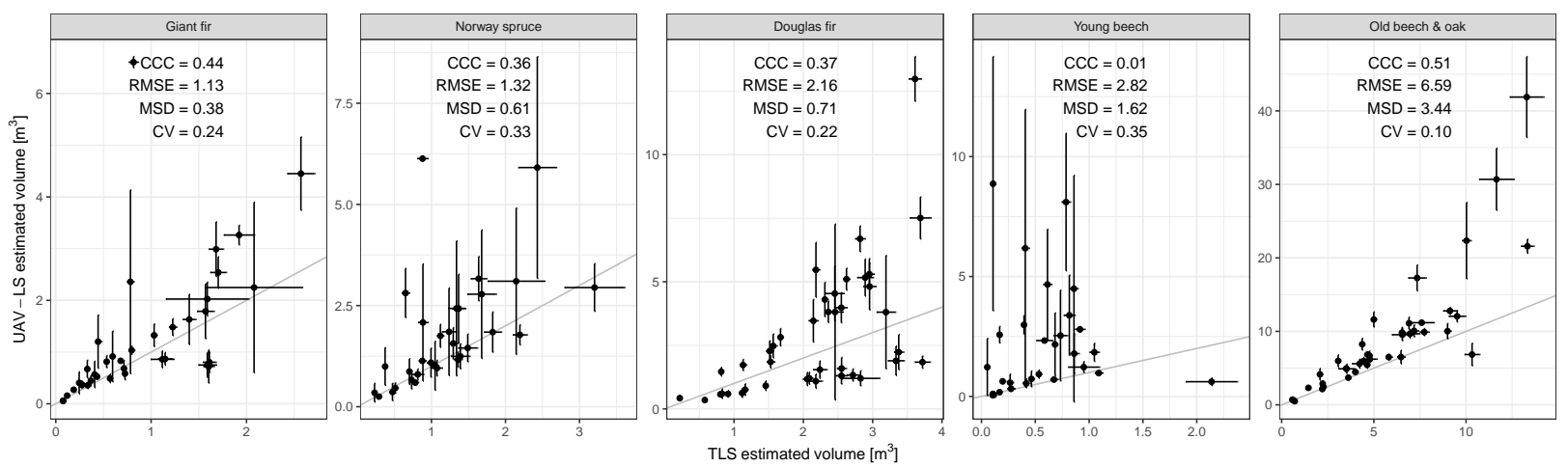

Figure 7: Tree volume reconstruction for UAV-LS compared to TLS. Error bars represent 1 standard deviation of the 10 QSM realisations. Grey lines are 1:1 match. CV is mean UAV-LS coefficient of variance. Positive MSD means overestimation by UAV-LS. RMSE and MSD in $\mathrm{m}^{3}$.
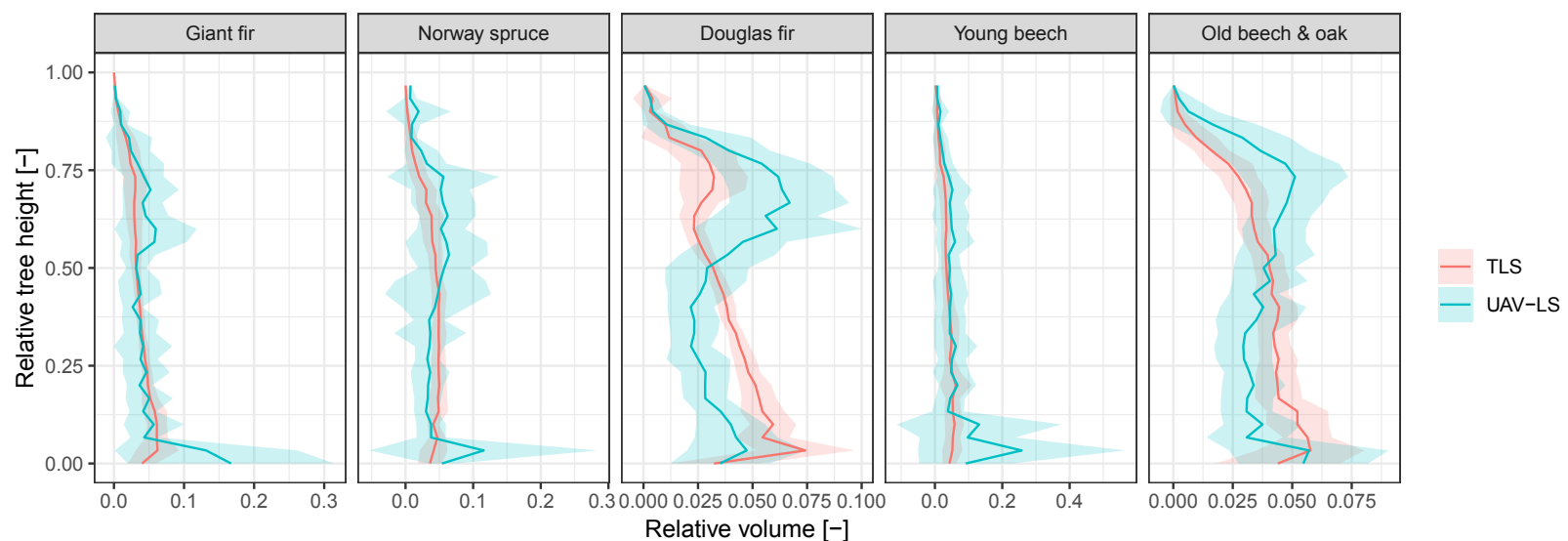

Figure 8: QSM volume aggregated over height. Solid centre lines represent the mean volume contribution of a height layer to the total tree volume. Relative tree height was based on the TLS point cloud height range. Coloured ribbons indicate 1 standard deviation from the mean. Each panel summarises all modelled trees of the corresponding stand. 


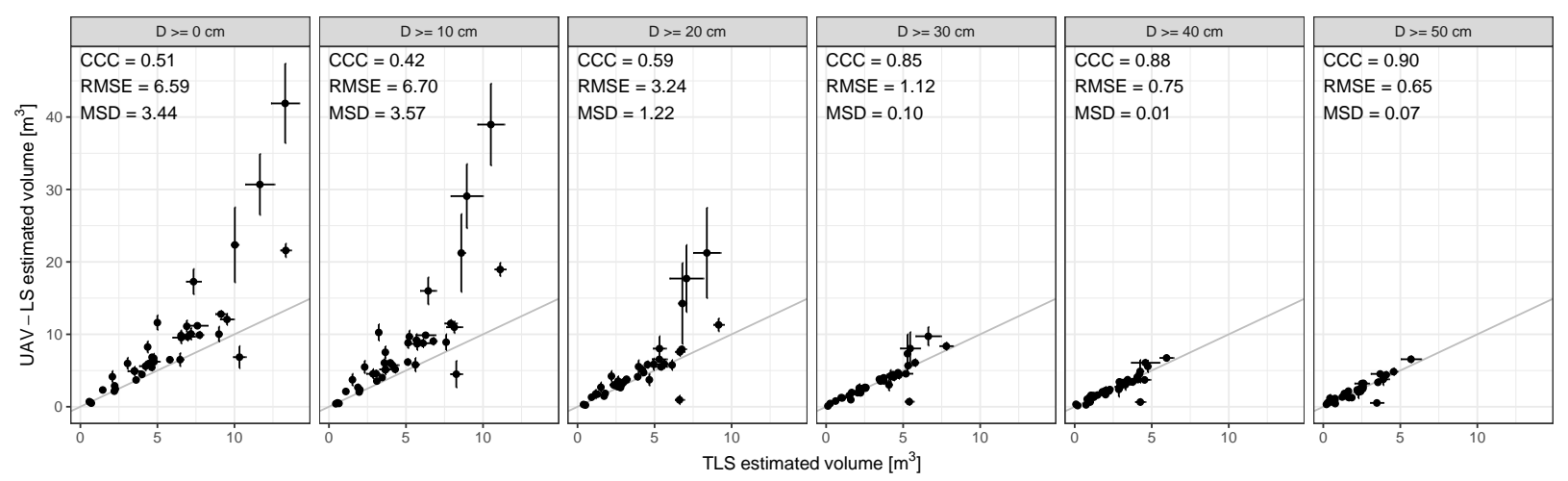

Figure 9: Accumulative tree volume for different diameter bins reconstruction for UAV-LS compared to TLS for old beech and oak trees. Error bars represent 1 standard deviation of the 10 QSM realisations. Grey lines are 1:1 match. Positive MSD means overestimation by UAV-LS. RMSE and MSD in $\mathrm{m}^{3}$.

The Douglas fir comprised the second largest trees in the study area with DBH of up to $56.5 \mathrm{~cm}$ diameter. It was most similar to old beech and oak stand with respect to canopy opennesses. Nonetheless, UAV-LS reconstruction was less successful here with lower CCC of 0.37 and higher CV of 0.22 . The bias in terms of MSD was with $0.71 \mathrm{~m}^{3}$ substantially lower than for the old beech and oak. However, this stemmed mainly from the cancelling effect of two groups, for which volume was over- and underestimated, respectively. The overestimation could be traced to the same mechanism as in the old beech and oak stand. The crown tended to be modelled with a high number of small cylinders. The effect on the vertical distribution of volume was even stronger than in the old beech and oak stand, with $49.1 \%$ of the total volume in the upper half of the tree in the case of UAV-LS compared to $25.7 \%$ in the case of TLS (Figure 8). The group of underestimated trees turned out to be positioned at the southern and south-western edges of the study area. Here, the effect was the same as for the single outlier in the old beech and oak stand. This means due to the location of the flight lines, the trees' southern sides could not be sensed from the UAV resulting in incomplete point clouds and QSMs with many small instead of few properly sized cylinders for trunks.

In the case of giant fir, UAV-LS agreed with TLS reconstructed models with CCC of 0.44 and RMSE of $1.13 \mathrm{~m}^{3}$. Outliers could not be explained by their position within the stand as was the case for the Douglas fir trees. In fact, this stand could be observed from a UAV-LS 
flight line outside of the stand in the North plus from the diagonal cross line (Figure 1), which provided better observations from multiple directions. The vertical distribution of volume indicated a similar bias as was the case for old beech, oak and Douglas fir, but with a much lower magnitude across the tree vertical profiles (Figure 8). The upper halves of trees contained $35.5 \%$ in the case of UAV-LS, while this was $25.6 \%$ for TLS.

Despite the similar levels of agreement of UAV-LS modelled control cylinders with TLS control cylinders between giant fir and Norway spruce (Section 4.3), Norway spruce modelled QSMs showed less agreement in terms of QSM volume with CCC of 0.36 and RMSE of $1.32 \mathrm{~m}^{3}$. Also, Norway spruce QSM models showed less modelling confidence than giant fir QSMs in terms of a higher CV of 0.33 for Norway spruce and 0.24 for giant fir. The denser tree coverage of the Norway spruce could be an explanation for that (Table 1), as it results in mutual shielding of trees from above canopy view points and therefore observation of lower and larger tree elements by UAV-LS. Additionally, the higher tree density leads to a lower number of points per tree.

The young beech stand showed the lowest comparability between UAV-LS and TLS QSMs with CCC of 0.01. Especially the RMSE of $2.14 \mathrm{~m}^{3}$ indicated low modelling performance with respect to the maximum individual TLS QSM volume of $0.84 \mathrm{~m}^{3}$. In particular, volume was generally overestimated with a MSD of $1.62 \mathrm{~m}^{3}$. When inspecting the corresponding point clouds, it became clear that the point density on the trunk and branch surfaces was too low to actually represent the volume of the individuals, i.e. points formed lines for trunks instead of covering them on multiple sites. In contrast to the old beeches, the young beech trees were positioned much denser (Table 1) and had already almost flushed all their leaves, which hindered visibility of the lower canopy elements.

\section{Discussion}

\subsection{Tree Segmentation}

Overall, UAV-LS point clouds show potential in combination with semi-automatic segmentation of trees. Even young trees in the understorey of the old beech and oak could be 
identified. This study used a combined approach that segmented both UAV-LS and TLS point clouds at the same time, both during automatic segmentation and during manual cleaning. If only UAV-LS point clouds were to be used, the automatic step would remain the same. However, the manual cleaning step would be affected to a certain extent. Crown parts of trees with interlocked branches would possibly be wrongly assigned to neighbouring trees, especially in complex canopies like the mature beech and oak stand. Nonetheless, the expected overall effect on tree wood volume estimation is low, because these edges typically consist of small branches. Additionally, this misclassification would have small effect on the overall estimated forest wood volume, since wrongly assigned parts would be modelled as branches on the neighbouring tree.

If a fully automatic approach is desired to achieve fast plot scale results, it can be said that recent automatic algorithms have moved away from incremental adaptation of initial algorithms and make more use of the characteristics of LiDAR data (Duncanson et al., 2014; Eysn et al., 2015; Zhen et al., 2016). Algorithms exploit more and more the full vertical profile of high density ALS point clouds (Strîmbu and Strîmbu, 2015) and can even deliver segmentation uncertainty (Parkan and Tuia, 2018). Wallace et al. (2014a) achieved detection rates of up to $98 \%$ with another UAV-LS system that produced point clouds with 50 points $/ \mathrm{m}^{2}$. This suggests that automatic detection and segmentation with the dataset underlying this study has the potential to achieve excellent segmentation results. These approaches should be targeted in the future.

\subsection{Foliage Filtering}

The foliage classification cross-validation with UAV-LS based on manually selected training samples generally produced high accuracies in this study (Table 3). However, a certain extent of foliage points remained that were subsequently modelled as small branches (Figure 5 and 6). This portion was larger for UAV-LS than for TLS and led to a much higher number of small cylinders in the upper crown for UAV-LS. Previous TLS-based studies using TreeQSM have skipped leaf-wood separation, but still achieved high correspondence with destructively measured AGB (Calders et al., 2015b; Gonzalez de Tanago et al., 2018; Lau 
et al., 2018). Together this suggests that foliage filtering prior to wood volume assessment with TreeQSM based on UAV-LS will require a higher attention in the future.

For improved classification of foliage, new classification approaches based on geometric features, e.g., local cluster orientation, have been proposed to overcome the ambiguity of radiometric LiDAR features (Zhu et al., 2018; Wang et al., 2018; Vicari et al., 2019). However, these methods rely on high density TLS point clouds and tests with lower density point clouds are still to be performed (Vicari et al., 2019). This is especially relevant for UAV-LS as observation geometry, point registration accuracy and point cloud density markedly differ from TLS. Another alternative for the whole volume estimation work-flow for coniferous species could be a hybrid approach as suggested by Stovall et al. (2017): they model stems of coniferous Pinus contorta explicitly with cylinders and make use of allometric relationships to estimate branch and needle biomass. Unfortunately, such an approach would require the establishment of an extensive database for foliage density allometric relationships.

\subsection{QSM Modelling}

The tree modelling performance of UAV-LS compared to TLS in this study needs to be regarded in the context of the challenges to produce accurate point clouds from a UAV platform. Four principal mechanisms come into question that have a stronger effect on UAV-LS point cloud accuracy than on TLS. First, the overall LiDAR sensor ranging accuracy and precision is lower for the VUX-1UAV than the VZ-400 (Table 2). This is likely to be the general case for miniaturised LiDAR sensors. However, LiDAR ranging accuracy is typically the smallest error source in the whole point cloud production chain, both for UAV-LS and TLS. It can only be improved by exchanging the LiDAR sensor with a higher quality device.

Second, the larger beam divergence of the VUX-1UAV additionally decreases point cloud accuracy. For example, at an average canopy height of $20 \mathrm{~m}$ and a flight height of $90 \mathrm{~m}$ the VUX-1UAV produces an effective footprint of $3.5 \mathrm{~cm}$ at the top of the canopy based on a beam divergence of $0.5 \mathrm{mrad}$ specified for long distances from the scanner. For short distance applications like in this study, the beam exit diameter, which was neglected here, 
will further increase the effective footprint. For the same canopy, the effective footprint would be $0.6 \mathrm{~cm}$ for the VZ-400 due to its closer distance to the canopy and smaller beam divergence of $0.3 \mathrm{mrad}$. This larger footprint for the VUX-1UAV leads to larger ambiguity in the point registration, hence lower spatial accuracy. This effect is also confirmed by the return statistics of the point clouds. On the one hand, UAV-LS returns were made up of a larger proportion of higher order returns, with up to $7^{\text {th }}$ order and only $14.6 \%$ single returns. On the other hand, the TLS point cloud contained only up to maximum $4^{\text {th }}$ order returns and $58.7 \%$ single returns. This suggests that UAV-LS returns were triggered at much lower return energy levels than TLS returns, i.e. when canopy elements only partially intercepted the beam, possibly at the beam edge. As is the case for the LiDAR ranging accuracy, beam divergence is bound to the system in use. Nevertheless, the effective footprint size can be reduced by flying at lower altitudes. In forest set-ups, the flight height lower limit is restricted by the tree height and UAV observing opportunities from openings for VLOS operation, influenced by local topography.

Third, the free moving mounting of the LiDAR on a UAV produces many more degrees of freedom for the scanner positioning and orientation. In this study, the trajectory was sampled at $200 \mathrm{~Hz}$ for a flight time of approximately $20 \mathrm{~min}$, resulting in roughly 240000 positions. For the TLS only 118 positions - 58 upright and 58 tilted - had to be estimated. For accurate co-registration of scan lines and scan positions, planar features extracted from the point clouds are usually used to achieve the fine registration (Wilkes et al., 2017). TLS point clouds with higher point density provide more opportunities to find those features, such as even trunk surfaces or ground patches. These have to be larger in size for UAV-LS with a lower point cloud density and are therefore rarer in forests. Additionally, UAV-LS registration has to be optimised within flight lines, which can be regarded as the equivalent to scan positions in TLS. Positioning and orientation errors can be controlled to some extent with the flight path planning, with straight flight lines delivering best results, and by avoiding weather conditions with strong gusts that abruptly change flight speed and orientation.

Fourth, the perspective of the TLS from below the canopy favours correct modelling of the trunk and lower branches. UAV-LS point clouds are less dense in this region, leading to 
higher uncertainty in cylinder fitting. These modelling errors at lower heights can propagate into higher areas of the canopy. Especially the upper crown becomes very difficult to model under these conditions.

All together, the above-mentioned factors determine a threshold on the diameter for modelling of branches. Here, a diameter of $30 \mathrm{~cm}$ appeared to be the threshold for reliable volume modelling with UAV-LS (Figure 9). Different thresholds have been observed in TLSbased studies using cylinder fitting approaches: Hackenberg et al. (2015) found that elements with diameter $\geq 10 \mathrm{~cm}$ can be modelled accurately, while elements with diameter $\leq 4 \mathrm{~cm}$ were often overestimated. Momo Takoudjou et al. (2018) modelled branches with diameter $\geq 5 \mathrm{~cm}$ reliable. However, Lau et al. (2018) found that TreeQSM reconstructed actual branching architecture as opposed to cumulative volume only for branches with diameter $\geq 30 \mathrm{~cm}$.

Additionally, the above results showed that canopy structure as exemplified by the different stands in this study has a significant impact on UAV-LS QSM modelling capability when modelled with TreeQSM. UAV-LS QSMs showed higher agreement in terms of tree volume with TLS in open stands, and decreasing agreement in denser stands or in stands with smaller trees. The direction of this trend can also be observed when using Structure from Motion (SfM) techniques of passive camera systems (Wallace et al., 2017). The principal effect behind this trend is increasing occlusion of canopy elements by other elements with increasing stand density. This is a well-known problem in TLS, and largely overcome by using multiple scan locations and co-registration (Wilkes et al., 2017). For UAV-LS, this effect was only recently quantified by Schneider et al. (2019) at the Laegern temperate forest site during leaf-on conditions. Up to a height of $25 \mathrm{~m}, 71 \%$ of all $10 \mathrm{~cm}^{3}$ voxels were occluded when viewed with a VUX-1UAV. Occlusion of trunks was probably the leading cause for cases of low QSM quality in the dense Giant fir and Norway spruce stands (Figure 7). Under these circumstances, the chosen flight paths with dominantly parallel lines (Figure 1) proved probably less optimal to overcome occlusion in these stands. A larger diversity of flight directions could make better use of canopy gaps to detect lower canopy elements like trunks. Due to the leaf-off conditions under which data were acquired in this study, occlusion caused by the deciduous species' leaves was largely avoided in this study. Nonetheless, 
UAV-LS showed low agreement with TLS QSMs in the upper crown parts of the beech and oak stand with on average $13.7 \%$ more relative tree volume attributed to the upper tree half for UAV-LS than for TLS (Figure 8), where occlusion should actually be low for UAV-LS. This suggests that other mechanisms like non-sufficient point registration accuracy in case of UAV-LS, led to ill registered branch points and subsequent low quality QSMs. On the side of TLS, observations probably suffered from occlusion of the upper canopy by lower branches and upper branches were omitted, which increased the disagreement between UAV-LS and TLS.

Still, the detection of small understorey trees and the moderate modelling success even in dense stands speak for the application of UAV-LS in complex vertically structured forests. In comparison to TLS, UAV-LS has the advantage of fast acquisition speed and thereby larger coverage of plot area. In this study, UAV-LS acquisition required $2 \mathrm{~h}$, while TLS took approximately $16 \mathrm{~h}$, which is factor of eight difference. This should be considered together with possible improvements to the UAV-LS processing chain.

There are some ways that possibly improve UAV-LS QSM agreement with TLS. First, repeated flights with point cloud acquisition over the study area would increase the number of points, which increases the chance to collect trunk returns in dense stands such as the giant fir and Norway spruce stands or to penetrate the foliage of the young beech stand. Second, varying flight patterns with different headings would improve the sampling of different trunk sides and prevent edge effects such as those observed for the Douglas firs (Section 4.4). Third, additional layout of ground control panels could improve the flight line-to-flight line registration and therefore internal consistency of the point cloud, which could improve the modelling of smaller branches. Fourth, in closed stands like the giant fir or Norway spruce stands fitting procedures that apply more constrains could be utilised. For instance, successful identification and modelling of the trunk as a single large cylinder or cone in these coniferous species would capture the larger part of total tree volume. Also slice-wise fitting as applied in Stovall et al. (2017) for the trunk could deliver more robust results. Pitkänen et al. (2019) present another complementary procedure for coniferous species that applies modelling and quality checking over height slices. UAV-LS control cylinders showed 
acceptable agreement with CCC of at least 0.93 (Figure 4), indicating that a large cylinder or cone-shaped geometry, or slice-wise fits could be successful.

\section{Conclusions}

Recent technological developments have allowed UAV-LS to produce high density point clouds. This study compares UAV-LS explicit tree modelling with a TLS benchmark in terms of tree volume estimation. UAV-LS point cloud acquisition was considerably faster than TLS at scales relevant for satellite AGB calibration and validation. In total, 200 trees of 5 stands have been segmented and automatically modelled. UAV-LS control cylinders, which were used during model selection, generally agreed well with TLS cylinders with RMSE in diameter between 2.26 and $7.90 \mathrm{~cm}$. Full tree volume based on reconstructed QSMs showed differences between the examined stands. Mature beech and oak volumes were reproduced best by UAV-LS with CCC of 0.51 and RMSE of $6.59 \mathrm{~m}^{3}$. Young beech trees showed lowest correspondence with CCC of 0.01 and RMSE of $2.82 \mathrm{~m}^{3}$. This pointed to the fact that canopy structure, in this case tree and branch size, branch arrangement and foliage, plays a major role in tree volume estimation capabilities. Also, the impact of flight path planning could be observed to some extent with improved volume modelling when trunks were observed from multiple sites. Future studies should aim to overcome the limitations in dense canopies by increasing the point cloud density through repeated flights and adapting the flight path with respect to maximising viewing angles on the trunks.

\section{Acknowledgements}

This work was carried out as part of the IDEAS+ contract funded by ESA-ESRIN. K.C. is funded by BELSPO (Belgian Science Policy Office) in the frame of the STEREO III programme - project 3D-FOREST (SR/02/355). A.L. and P.R. are supported by the ERA-NET FACCE ERA-GAS NWO-3DforMod project (ANR-17-EGAS-0002-01). FACCE ERA-GAS has received funding from the European Union's Horizon 2020 research and innovation programme under grant agreement No 696356. The access to the RiCOPTER 
has been made possible by Shared Research Facilities of Wageningen University Research. The authors thank the Dutch Forestry Service (Staatsbosbeheer) for granting access to the site and 06-GPS for supplying the GNSS base station data. Further thanks go to Marcello Novani for help during the fieldwork and Jan den Ouden to identify the tree species. We thank two anonymous reviewers for their constructive comments on the manuscript.

\section{References}

Baccini, A., Goetz, S.J., Walker, W.S., Laporte, N.T., Sun, M., Sulla-Menashe, D., Hackler, J., Beck, P.S., Dubayah, R., Friedl, M.A., Samanta, S., Houghton, R.A., 2012. Estimated carbon dioxide emissions from tropical deforestation improved by carbon-density maps. Nature Climate Change 2, 182-185. URL: http://dx.doi.org/10.1038/nclimate1354, doi:10.1038/nclimate1354, arXiv:1504.00980.

Balsi, M., Esposito, S., Fallavollita, P., Nardinocchi, C., 2018. Single-tree detection in high-density LiDAR data from UAV-based survey. European Journal of Remote Sensing 51, 679-692. URL: https://www.tandfonline.com/doi/full/10.1080/22797254.2018.1474722, doi:10.1080/22797254 . 2018.1474722 .

Belgiu, M., Drăgu, L., 2016. Random forest in remote sensing: A review of applications and future directions. ISPRS Journal of Photogrammetry and Remote Sensing 114, 24-31. doi:10.1016/j.isprsjprs.2016.01. 011.

Brede, B., Bartholomeus, H., Suomalainen, J., Clevers, J., Verbesselt, J., Herold, M., Culvenor, D., Gascon, F., 2016. The Speulderbos Fiducial Reference Site for Continuous Monitoring of Forest Biophysical Variables, in: Living Planet Symposium 2016, Prague, Czech Republic, 9-13 May 2016, Prague. p. 5.

Brede, B., Lau, A., Bartholomeus, H.M., Kooistra, L., 2017. Comparing RIEGL RiCOPTER UAV LiDAR Derived Canopy Height and DBH with Terrestrial LiDAR. Sensors 17, 2371. URL: http://www. mdpi . com/1424-8220/17/10/2371, doi:10.3390/s17102371.

Breiman, L., 2001. Random forests. Machine Learning 45, 5-32. doi:10.1023/A:1010933404324, arXiv:/dx.doi.org/10.1023\%2FA\%3A1010933404324.

Calders, K., Burt, A., Newnham, G., Disney, M., Murphy, S., Raumonen, P., Herold, M., Culvenor, D., Armston, J., Avitabile, V., Kaasalainen, M., 2015a. Reducing uncertainties in above-ground biomass estimates using terrestrial laser scanning, in: Proceedings of the 2015 SilviLaser, La Grande Motte, France, 28-30 September 2015, pp. 197-199.

Calders, K., Disney, M.I., Armston, J., Burt, A., Brede, B., Origo, N., Muir, J., Nightingale, J., 2017. Evaluation of the Range Accuracy and the Radiometric Calibration of Multiple Terrestrial Laser Scanning 
Instruments for Data Interoperability. IEEE Transactions on Geoscience and Remote Sensing 55, 2716-2724. URL: http://ieeexplore.ieee.org/document/7858757/, doi:10.1109/TGRS.2017.2652721.

Calders, K., Newnham, G., Burt, A., Murphy, S., Raumonen, P., Herold, M., Culvenor, D., Avitabile, V., Disney, M., Armston, J., Kaasalainen, M., 2015b. Nondestructive estimates of above-ground biomass using terrestrial laser scanning. Methods in Ecology and Evolution 6, 198-208. URL: http://doi.wiley. com/10.1111/2041-210X.12301, doi:10.1111/2041-210x.12301.

Calders, K., Origo, N., Burt, A., Disney, M., Nightingale, J., Raumonen, P., Åkerblom, M., Malhi, Y., Lewis, P., 2018. Realistic Forest Stand Reconstruction from Terrestrial LiDAR for Radiative Transfer Modelling. Remote Sensing 10, 933. URL: http://www.mdpi.com/2072-4292/10/6/933, doi:10.3390/RS10060933. Ciais, P., Sabine, C., Bala, G., Bopp, L., Brovkin, V., Canadell, J., Chhabra, A., DeFries, R., Galloway, J., Heimann, M., Jones, C., Quéré, C.L., Myneni, R., Piao, S., Thornton, P., 2013. Carbon and Other Biogeochemical Cycles, in: Stocker, T., Qin, D., Plattner, G.K., Tignor, M., Allen, S., Boschung, J., Nauels, A., Xia, Y., Bex, V., Midgle, P. (Eds.), Climate Change 2013: The Physical Science Basis. Contribution of Working Group I to the Fifth Assessment Report of the Intergovernmental Panel on Climate Change. Cambridge University Press, Cambridge, United Kingdom and New York, NY, USA, pp. 465-570.

Disney, M.I., Boni Vicari, M., Burt, A., Calders, K., Lewis, S.L., Raumonen, P., Wilkes, P., 2018. Weighing trees with lasers: advances, challenges and opportunities. Interface Focus 8, 20170048. URL: http://rsfs . royalsocietypublishing.org/lookup/doi/10.1098/rsfs.2017.0048, doi:10.1098/rsfs .2017.0048.

Duncanson, L.I., Cook, B.D., Hurtt, G.C., Dubayah, R.O., 2014. An efficient, multi-layered crown delineation algorithm for mapping individual tree structure across multiple ecosystems. Remote Sensing of Environment 154, 378-386. URL: http://dx.doi.org/10.1016/j.rse.2013.07.044, doi:10.1016/j.rse.2013.07. 044.

Eysn, L., Hollaus, M., Lindberg, E., Berger, F., Monnet, J.M., Dalponte, M., Kobal, M., Pellegrini, M., Lingua, E., Mongus, D., Pfeifer, N., 2015. A benchmark of lidar-based single tree detection methods using heterogeneous forest data from the Alpine Space. Forests 6, 1721-1747. doi:10.3390/f6051721.

Fernandes, R., Plummer, S., Nightingale, J., Baret, F., Camacho, F., Fang, H., Garrigues, S., Gobron, N., Lang, M., Lacaze, R., LeBlanc, S., Meroni, M., Martinez, B., Nilson, T., Pinty, B., Pisek, J., Sonnentag, O., Verger, A., Welles, J., Weiss, M., Widlowski, J., 2014. Global Leaf Area Index Product Validation Good Practices, in: Schaepman-Strub, G., Román, M., Nickeson, J. (Eds.), Best Practice for SatelliteDerived Land Product Validation. 2.0.1 ed.. Land Product Validation Subgroup (WGCV/CEOS), p. 76. doi:10.5067/doc/ceoswgcv/lpv/lai.002.

Gonzalez de Tanago, J., Lau, A., Bartholomeus, H., Herold, M., Avitabile, V., Raumonen, P., Martius, C., Goodman, R.C., Disney, M., Manuri, S., Burt, A., Calders, K., 2018. Estimation of above-ground biomass of large tropical trees with terrestrial LiDAR. Methods in Ecology and Evolution 9, 223-234. 
URL: http://doi.wiley.com/10.1111/2041-210X.12904, doi:10.1111/2041-210X.12904.

Guo, Q., Su, Y., Hu, T., Zhao, X., Wu, F., Li, Y., Liu, J., Chen, L., Xu, G., Lin, G., Zheng, Y., Lin, Y., Mi, X., Fei, L., Wang, X., 2017. An integrated UAV-borne lidar system for 3D habitat mapping in three forest ecosystems across China. International Journal of Remote Sensing 38, 1-19. URL: https://www.tandfonline.com/doi/full/10.1080/01431161.2017.1285083, doi:10.1080/01431161. 2017.1285083.

Hackenberg, J., Wassenberg, M., Spiecker, H., Sun, D., 2015. Non destructive method for biomass prediction combining TLS derived tree volume and wood density. Forests 6, 1274-1300. doi:10.3390/f6041274.

Heinzel, J., Huber, M., 2016. Detecting Tree Stems from Volumetric TLS Data in Forest Environments with Rich Understory. Remote Sensing 9, 9. URL: http://www.mdpi.com/2072-4292/9/1/9, doi:10.3390/ rs9010009.

Houghton, R.A., Hall, F., Goetz, S.J., 2009. Importance of biomass in the global carbon cycle. Journal of Geophysical Research: Biogeosciences 114, 1-13. doi:10.1029/2009JG000935.

Jaakkola, A., Hyyppä, J., Kukko, A., Yu, X., Kaartinen, H., Lehtomäki, M., Lin, Y., 2010. A low-cost multi-sensoral mobile mapping system and its feasibility for tree measurements. ISPRS Journal of Photogrammetry and Remote Sensing 65, 514-522. URL: http://dx.doi.org/10.1016/j.isprsjprs . 2010.08.002, doi:10.1016/j.isprsjprs.2010.08.002.

Keller, M., Palace, M., Hurtt, G., 2001. Biomass estimation in the Tapajos National Forest, Brazil. Forest Ecology and Management 154, 371-382. URL: http://linkinghub.elsevier.com/retrieve/ pii/S0378112701005096, doi:10.1016/S0378-1127(01)00509-6.

Koch, B., Heyder, U., Weinacker, H., 2006. Detection of Individual Tree Crowns in Airborne Lidar Data. Photogrammetric Engineering \& Remote Sensing 72, 357-363. URL: http://openurl . ingenta.com/content/ xref?genre=article $\{\&\}$ issn=0099-1112 $\{\&\}$ volume $=72\{\&\}$ issue $=4\{\&\}$ spage $=357$, doi: $10.14358 /$ PERS . 72.4 .357

Lau, A., Bentley, L.P., Martius, C., Shenkin, A., Bartholomeus, H., Raumonen, P., Malhi, Y., Jackson, T., Herold, M., 2018. Quantifying branch architecture of tropical trees using terrestrial LiDAR and 3D modelling. Trees 32, 1219-1231. URL: http://dx.doi.org/10.1007/s00468-018-1704-1http: //link.springer.com/10.1007/s00468-018-1704-1, doi:10.1007/s00468-018-1704-1.

Le Toan, T., Quegan, S., Davidson, M.W.J., Balzter, H., Paillou, P., Papathanassiou, K., Plummer, S., Rocca, F., Saatchi, S., Shugart, H., Ulander, L., 2011. The BIOMASS mission: Mapping global forest biomass to better understand the terrestrial carbon cycle. Remote Sensing of Environment 115, 2850-2860. URL: http://dx.doi.org/10.1016/j.rse.2011.03.020, doi:10.1016/j.rse.2011.03.020.

Lin, L.I.K., 1989. A Concordance Correlation Coefficient to Evaluate Reproducibility. Biometrics 45, 255. URL: https ://www . jstor .org/stable/2532051?origin=crossref, doi:10.2307/2532051. 
Mandlburger, G., Hollaus, M., Glira, P., Wieser, M., Riegl, U., Pfennigbauer, M., 2015. First examples from the RIEGL VUX-SYS for forestry applications, in: Proceedings of Silvilaser, La Grande Motte, France. pp. 105-107.

Mitchard, E.T., Feldpausch, T.R., Brienen, R.J., Lopez-Gonzalez, G., Monteagudo, A., Baker, T.R., Lewis, S.L., Lloyd, J., Quesada, C.A., Gloor, M., ter Steege, H., Meir, P., Alvarez, E., Araujo-Murakami, A., Aragão, L.E., Arroyo, L., Aymard, G., Banki, O., Bonal, D., Brown, S., Brown, F.I., Cerón, C.E., Chama Moscoso, V., Chave, J., Comiskey, J.A., Cornejo, F., Corrales Medina, M., Da Costa, L., Costa, F.R., Di Fiore, A., Domingues, T.F., Erwin, T.L., Frederickson, T., Higuchi, N., Honorio Coronado, E.N., Killeen, T.J., Laurance, W.F., Levis, C., Magnusson, W.E., Marimon, B.S., Marimon Junior, B.H., Mendoza Polo, I., Mishra, P., Nascimento, M.T., Neill, D., Núñez Vargas, M.P., Palacios, W.A., Parada, A., Pardo Molina, G., Peña-Claros, M., Pitman, N., Peres, C.A., Poorter, L., Prieto, A., Ramirez-Angulo, H., Restrepo Correa, Z., Roopsind, A., Roucoux, K.H., Rudas, A., Salomão, R.P., Schietti, J., Silveira, M., de Souza, P.F., Steininger, M.K., Stropp, J., Terborgh, J., Thomas, R., Toledo, M., Torres-Lezama, A., Van Andel, T.R., van der Heijden, G.M., Vieira, I.C., Vieira, S., Vilanova-Torre, E., Vos, V.A., Wang, O., Zartman, C.E., Malhi, Y., Phillips, O.L., 2014. Markedly divergent estimates of Amazon forest carbon density from ground plots and satellites. Global Ecology and Biogeography 23, 935-946. doi:10.1111/geb.12168.

Momo Takoudjou, S., Ploton, P., Sonké, B., Hackenberg, J., Griffon, S., de Coligny, F., Kamdem, N.G., Libalah, M., Mofack, G.I., Le Moguédec, G., Pélissier, R., Barbier, N., 2018. Using terrestrial laser scanning data to estimate large tropical trees biomass and calibrate allometric models: A comparison with traditional destructive approach. Methods in Ecology and Evolution 9, 905-916. URL: http: //doi.wiley.com/10.1111/2041-210X.12933, doi:10.1111/2041-210X.12933, arXiv:0608246v3.

Parkan, M., Tuia, D., 2018. Estimating Uncertainty of Point-Cloud Based Single-Tree Segmentation with Ensemble Based Filtering. Remote Sensing 10, 335. doi:10.3390/rs10020335.

Pitkänen, T.P., Raumonen, P., Kangas, A., 2019. Measuring stem diameters with TLS in boreal forests by complementary fitting procedure. ISPRS Journal of Photogrammetry and Remote Sensing 147, 294-306. URL: https://doi.org/10.1016/j.isprsjprs.2018.11.027, doi:10.1016/j.isprsjprs.2018.11.027.

Rabbani, T., Heuvel, F.V.D., 2005. Efficient Hough Transform for Automatic Detection of Cylinders in Point Clouds. ISPRS Workshop on Laser Scanning 3, 60-65. URL: http://citeseerx.ist.psu.edu/ viewdoc/download?doi=10.1.1.118.1736\{\&\}rep=rep1\{\&\}type=pdf, doi:10.1.1.118.1736

Rahman, M.Z.A., Bakar, M.A.A., Razak, K.A., Rasib, A.W., Kanniah, K.D., Kadir, W.H.W., Omar, H., Faidi, A., Kassim, A.R., Latif, Z.A., 2017. Non-destructive, laser-based individual tree aboveground biomass estimation in a tropical rainforest. Forests 8. doi:10.3390/f8030086.

Raumonen, P., Kaasalainen, M., Åkerblom, M., Kaasalainen, S., Kaartinen, H., Vastaranta, M., Holopainen, M., Disney, M., Lewis, P., 2013. Fast Automatic Precision Tree Models from Terrestrial Laser Scanner 
Data. Remote Sensing 5, 491-520. URL: http://www.mdpi.com/2072-4292/5/2/491/, doi:10.3390/ rs5020491.

Saatchi, S.S., Harris, N.L., Brown, S., Lefsky, M., Mitchard, E.T.A., Salas, W., Zutta, B.R., Buermann, W., Lewis, S.L., Hagen, S., Petrova, S., White, L., Silman, M., Morel, A., 2011. Benchmark map of forest carbon stocks in tropical regions across three continents. Proceedings of the National Academy of Sciences 108, 98999904. URL: http://www.pnas .org/content/108/24/9899. abstract, doi:10.1073/pnas.1019576108.

Schneider, F.D., Kükenbrink, D., Schaepman, M.E., Schimel, D.S., Morsdorf, F., 2019. Quantifying 3D structure and occlusion in dense tropical and temperate forests using close-range LiDAR. Agricultural and Forest Meteorology 268, 249-257. URL: https://doi.org/10.1016/j.agrformet.2019.01.033, doi:10.1016/j.agrformet.2019.01.033.

Stoval, A., Shugart, H.H., 2018. Improved Biomass Calibration and Validation With Terrestrial LiDAR: Implications for Future LiDAR and SAR Missions. IEEE Journal of Selected Topics in Applied Earth Observations and Remote Sensing 11. doi:10.1109/JSTARS.2018.2803110.

Stovall, A.E.L., Vorster, A.G., Anderson, R.S., Evangelista, P.H., Shugart, H.H., 2017. Non-destructive aboveground biomass estimation of coniferous trees using terrestrial LiDAR. Remote Sensing of Environment 200, 31-42. URL: http://dx.doi.org/10.1016/j.rse.2017.08.013, doi:10.1016/j.rse.2017.08.013.

Strîmbu, V.F., Strîmbu, B.M., 2015. A graph-based segmentation algorithm for tree crown extraction using airborne LiDAR data. ISPRS Journal of Photogrammetry and Remote Sensing 104, 30-43. doi:10.1016/ j.isprsjprs.2015.01.018.

Thiel, C., Schmullius, C., 2016. The potential of ALOS PALSAR backscatter and InSAR coherence for forest growing stock volume estimation in Central Siberia. Remote Sensing of Environment 173, 258-273. URL: http://dx.doi.org/10.1016/j.rse.2015.10.030, doi:10.1016/j.rse.2015.10.030.

Vicari, M.B., Disney, M., Wilkes, P., Burt, A., Calders, K., Woodgate, W., 2019. Leaf and wood classification framework for terrestrial LiDAR point clouds. Methods in Ecology and Evolution, 1-15URL: http: //doi.wiley.com/10.1111/2041-210X.13144, doi:10.1111/2041-210X.13144.

Wallace, L., Hillman, S., Reinke, K., Hally, B., 2017. Non-destructive estimation of above-ground surface and near-surface biomass using 3D terrestrial remote sensing techniques. Methods in Ecology and Evolution 8, 1607-1616. URL: http://doi.wiley.com/10.1111/2041-210X.12759, doi:10.1111/2041-210X.12759.

Wallace, L., Lucieer, A., Watson, C., Turner, D., 2012. Development of a UAV-LiDAR system with application to forest inventory. Remote Sensing 4, 1519-1543. doi:10.3390/rs4061519.

Wallace, L., Lucieer, A., Watson, C.S., 2014a. Evaluating tree detection and segmentation routines on very high resolution UAV LiDAR data. IEEE Transactions on Geoscience and Remote Sensing 52, 7619-7628. doi:10.1109/TGRS. 2014.2315649. 
Wallace, L., Musk, R., Lucieer, A., 2014b. An assessment of the repeatability of automatic forest inventory metrics derived from UAV-borne laser scanning data. IEEE Transactions on Geoscience and Remote Sensing 52, 7160-7169. doi:10.1109/TGRS.2014.2308208.

Wang, D., Brunner, J., Ma, Z., Lu, H., Hollaus, M., Pang, Y., Pfeifer, N., 2018. Separating Tree Photosynthetic and Non-Photosynthetic Components from Point Cloud Data Using Dynamic Segment Merging. Forests 9, 252. URL: http://www .mdpi.com/1999-4907/9/5/252, doi:10.3390/f9050252.

Wei, L., Yang, B., Jiang, J., Cao, G., Wu, M., 2017. Vegetation filtering algorithm for UAV-borne lidar point clouds: a case study in the middle-lower Yangtze River riparian zone. International Journal of Remote Sensing 38, 1-12. URL: https://www.tandfonline.com/doi/full/10.1080/01431161 .2016.1252476, doi:10.1080/01431161.2016.1252476.

Wieser, M., Mandlburger, G., Hollaus, M., Otepka, J., Glira, P., Id, N.P., 2017. A Case Study of UAS Borne Laser Scanning for Measurement of Tree Stem Diameter. Remote Sensing 9, 1-11. doi:10.3390/rs9111154. Wilkes, P., Lau, A., Disney, M.I., Calders, K., Burt, A., Gonzalez de Tanago, J., Bartholomeus, H., Brede, B., Herold, M., 2017. Data Acquisition Considerations for Terrestrial Laser Scanning of Forest Plots. Remote Sensing of Environment 196, 140-153. URL: http://dx.doi.org/10.1016/j.rse.2017.04.030, doi:10.1016/j.rse.2017.04.030

Yuen, J.Q., Fung, T., Ziegler, A.D., 2016. Review of allometric equations for major land covers in SE Asia: Uncertainty and implications for above- and below-ground carbon estimates. Forest Ecology and Management 360,323-340. URL: http://dx.doi.org/10.1016/j.foreco.2015.09.016, doi:10.1016/ j.foreco.2015.09.016.

Zhen, Z., Quackenbush, L.J., Zhang, L., 2016. Trends in automatic individual tree crown detection and delineation-evolution of LiDAR data. Remote Sensing 8, 1-26. doi:10.3390/rs8040333.

Zhu, X., Skidmore, A.K., Darvishzadeh, R., Niemann, K.O., Liu, J., Shi, Y., Wang, T., 2018. Foliar and woody materials discriminated using terrestrial LiDAR in a mixed natural forest. International Journal of Applied Earth Observation and Geoinformation 64, 43-50. URL: http://dx.doi.org/10.1016/j.jag. 2017.09.004, doi:10.1016/j.jag.2017.09.004. 